Check for updates

Cite this: RSC Adv., 2018, 8, 21948

Received 28th March 2018 Accepted 10th June 2018

DOI: $10.1039 / c 8 r a 02685 h$

rsc.li/rsc-advances

\section{Polymer composites based on hexagonal boron nitride and their application in thermally conductive composites}

\author{
Cuiping Yu, ${ }^{\text {ab }}$ Jun Zhang, ${ }^{b}$ Wei Tian, ${ }^{* a}$ Xiaodong Fan ${ }^{a}$ and Yagang Yao (D) *b
}

\begin{abstract}
Hexagonal boron nitride ( $\mathrm{h}-\mathrm{BN}$ ) is also referred to as "white graphite". Owing to its two-dimensional planar structure, its thermal conductivity along and perpendicular to a basal plane is anisotropic. However, h-BN exhibits properties that are distinct from those of graphite, such as electric insulation, superior antioxidative ability, and purely white appearance. These qualities render h-BN superior as a filler in composites that require thermal conductivity while exhibiting electric insulation. Since the thermal performance of composites is mainly affected by thermal pathways, this article begins with an overall introduction of the preparation of boron nitride nanosheets, followed by a review of the fabrication of $\mathrm{h}$-BN-filled composites. Lastly, the construction of thermally conductive networks is discussed.
\end{abstract}

\section{Introduction}

With the miniaturization and high-degree integration of modern electric devices, high performance packaging materials are urgent in thermal management to guarantee the performance and reliability of the devices. ${ }^{\mathbf{1 - 3}}$ Two-dimensional (2D)

${ }^{a}$ The Key Laboratory of Space Applied Physics and Chemistry, Ministry of Education and Shaanxi Key Laboratory of Macromolecular Science and Technology, School of Science, Northwestern Polytechnical University, Xi'an 710072, PR China. E-mail: happytw_3000@nwpu.edu.cn

${ }^{b}$ Division of Advanced Nanomaterials, Key Laboratory of Nanodevices and Applications, Joint Key Laboratory of Functional Nanomaterials and Devices, CAS Center for Excellence in Nanoscience, Suzhou Institute of Nano-tech and Nanobionics, Chinese Academy of Sciences, Suzhou 215123, PR China. E-mail: ygyao2013@sinano.ac.cn materials were recently used as a new platform for thermal management applications due to their fascinating thermal properties, such as high in-plane thermal conductivity and the relatively low out-of-plane values. ${ }^{4}$ This could be ascribed to the covalent intra-layer bonds and van der Waals layer-to-layer interactions in 2D materials. For example, since graphene possesses high in-plane thermal conductivity $\left(\sim 5300 \mathrm{~W} \mathrm{~m}^{-1}\right.$ $\mathrm{K}^{-1}$ ), the thermal conductivity of the target composites increased significantly with the addition of only a small amount of graphene. ${ }^{5,6}$ Black phosphorus, as a new member of $2 \mathrm{D}$ materials, exhibited an anisotropy thermal conductivity $(\sim 20$ and $\sim 40 \mathrm{~W} \mathrm{~m}^{-1} \mathrm{~K}^{-1}$ for the armchair and zigzag configurations, respectively). ${ }^{7}$ However, they unavoidably make the target composites electrically conductive, which could not apply in electric equipment that need thermally conductive and electric

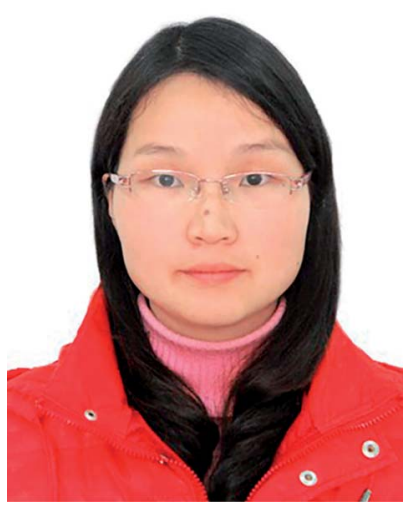

Cuiping $Y u$ received her $B S$ degree in 2012 from Hubei University. Currently she is a PhD candidate majoring in chemistry from Northwestern Polytechnical University. She is doing her research work in Suzhou Institute of Nano-Tech and Nano-Bionics, Chinese Academy of Sciences as an exchange student since 2015. Her research is focused on controlled preparation of aligned boron nitride/ polymer composites and their applications in thermal management.

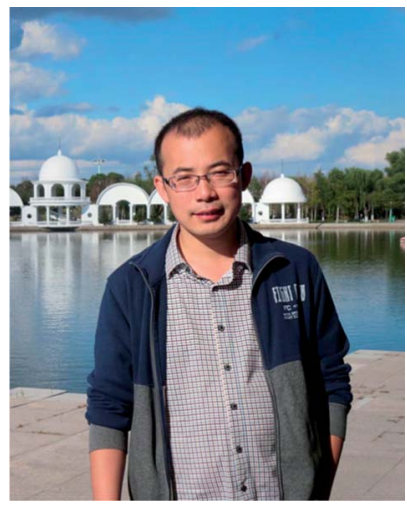

Jun Zhang obtained his PhD degree (2013) in Lanzhou Institute of Chemical Physics, Chinese Academy of Sciences, China. After his PhD degree, he conducted research at Shan $X i$ Normal University. At present, he worked as a post-doctoral researcher in Suzhou Institute of Nano-Tech and Nano-Bionics, Chinese Academy of Sciences. His research is focused on the novel semiconductor and its applications. 
insulating. Hexagonal boron nitride (h-BN), also called as white graphite, is an electrical insulator with a dielectric constant $3 \sim 4 .^{8}$ This make it suitable for the applications in thermal management of the electronics devices and displays that are not possible for graphene and black phosphorus. Thus, inorganic ceramic h-BN were designed to fabricate various insulating composites with superior thermal conductivity. ${ }^{9-11}$

Boron nitride (BN) consists of boron (B) and nitrogen (N) atoms in equal amounts and is arranged in a honeycomb configuration. The materials are mainly prepared from $\mathrm{B}$, boric acid $\left(\mathrm{H}_{3} \mathrm{BO}_{3}\right)$, or boron trioxide $\left(\mathrm{B}_{2} \mathrm{O}_{3}\right)$. BN exhibit 3 crystalline forms: h-BN (a layered structure like graphite), cubic BN (c-BN, similar to diamond), and wurtzite $\mathrm{BN}$ (w-BN, analogous to lonsdaleite). Among the $3 \mathrm{BN}$ phases, h-BN is the most stable under standard conditions and is a $\mathrm{sp}^{2}$-hybridized 2D-layered insulator. Within a $2 \mathrm{D}$ layer, the $\mathrm{B}$ and $\mathrm{N}$ atoms are alternatively bonded

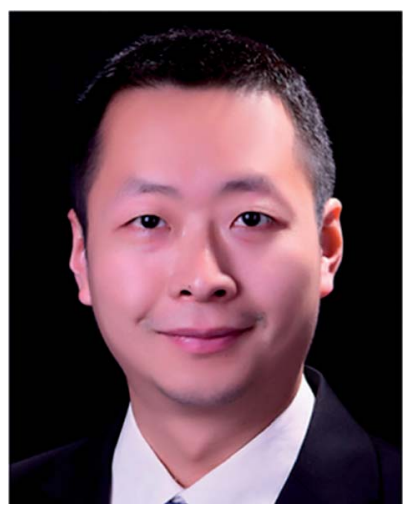

Wei Tian completed his PhD in Polymer Materials at Northwestern Polytechnical University in 2009 under the supervision of Professor Xiaodong Fan. He pursued his research work on Polymer Chemistry as a postdoctoral researcher at the same University till 2010. Following academic appointments at Northwestern Polytechnical University, he joined Department of Industrial and Systems Engineering at the Hong Kong Polytechnic University as a Research Associate. He came back to Northwestern Polytechnical University in 2011, and became a full professor in 2014. His scientific interests focus on supramolecular hyperbranched polymers and macromolecular self-assembly.

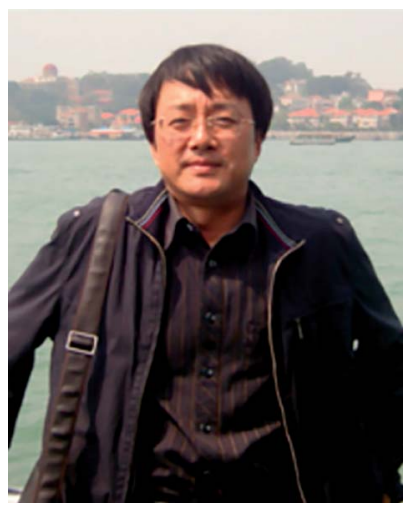

Xiaodong Fan received the $B S$ degree in 1985 from Harbin University of Science and Technology, and the PhD degree in Polymer Science from Université Laval, Canada in 1994. He was a Post-Doctoral Fellow in Polymer Materials, UC Davis, United States, from 1994 to 1996. Then he was a Post-Doctoral Fellow in Polymer Materials, Georgia Institute of Technology, USA, from 1996 to 1998. He is currently a Full Professor with the Northwestern Polytechnical University. His current research interests include biomedical topological polymers, national defense military measurement standard material, thermoplastic elastomers, petroleum pipe repair materials. together by robust B-N covalent bonds, while the $2 \mathrm{D}$ layers are stacked with each other via weak van der Waals forces. B-N bonds are partially ionic owing to the higher electronegativity of the $\mathrm{N}$ atom, which varies from the pure covalent $\mathrm{C}-\mathrm{C}$ bonds in a graphitic structure. The strong ionic bond of h-BN renders h-BN more difficult to exfoliate and functionalize than graphite. The crystallographic parameters of h-BN are $a=0.250 \mathrm{~nm}$ and $c=$ $0.666 \mathrm{~nm}$, and the interlayer spacing is $0.333 \mathrm{~nm}$. These characteristics allow h-BN to interact with graphene, enabling potential applications in many devices.

Owing to its distinct features, h-BN exhibits various properties, such as anisotropy parallel and perpendicular to a basal plane, ${ }^{12-14}$ constant wide band gap $(\sim 5.97 \mathrm{eV}),{ }^{15}$ superior antioxidative and structural stabilities (high thermal stability of up to $1000{ }^{\circ} \mathrm{C}$ in air and $1400{ }^{\circ} \mathrm{C}$ in vacuum), ${ }^{16}$ high thermal conductivity ( $600 \mathrm{~W} \mathrm{~m} \mathrm{~m}^{-1} \mathrm{~K}^{-1}$ for the in-plane direction, $30 \mathrm{~W}$ $\mathrm{m}^{-1} \mathrm{~K}^{-1}$ for the out-of-plane direction), ${ }^{12}$ and superior thermal expansion coefficient (1-, 2-, and 9-layer boron nitride nanosheets (BNNSs) showed the thermal expansion coefficient of about $-3.41 \times 10^{-2},-3.15 \times 10^{-2}$, and $-3.78 \times 10^{-2}(\mathrm{~cm} \mathrm{~K})^{-1}$, respectively), ${ }^{17}$ as well as superior mechanical properties (elastic constant of $220-510 \mathrm{~N} \mathrm{~m}^{-1}$ and Young's modulus $\left.\sim 1 \mathrm{TPa}\right){ }^{18,19}$ These characteristics render h-BN as an excellent filler in thermally conductive while electric insulating composites.

In this review, we first describe recent advances in the preparation of boron nitride nanosheets (BNNSs) as well as the fabrication of h-BN-based composites. The construction of thermally conductive networks is then reviewed based on their different thermally conductive pathways, followed by the summary and outlook.

\section{Preparation of BNNSs}

BNNSs are prepared using numerous synthesis methods, most of which are similar to well-established techniques in preparing corresponding carbon materials, with minor modifications.

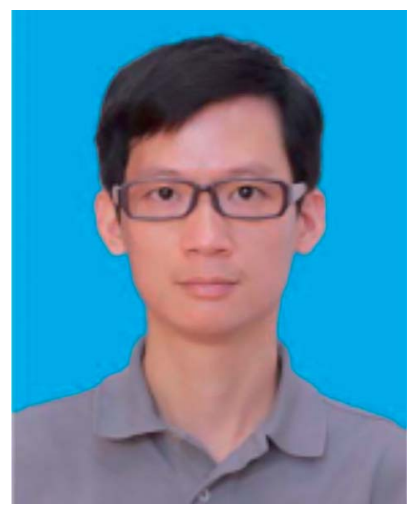

Yagang Yao received the $B S$ degree in chemistry from Lanzhou University, Lanzhou in 2004, and the PhD degree in physical chemistry from Peking University in 2009. He was a Post-Doctoral Fellow with the Materials Science and Engineering Department, Georgia Institute of Technology, Atlanta, GA, USA, from 2009 to 2013. He is currently a Full Professor with the Suzhou Institute of NanoTech and Nano-Bionics, Chinese Academy of Science. His current research interests include polymeric electronic materials, nanocomposites, thermal management in $3 D$ microelectronic and optoelectronic systems, and next-generation electrode materials in energy storage systems. 
Among the preparation methods reported, mechanical exfoliation, liquid exfoliation, chemical vapor deposition (CVD), and epitaxy are the most widely studied. In this section, some of these methods are briefly reviewed.

Mechanical exfoliation consists of direct mechanical exfoliation $^{20-22}$ and other exfoliation methods by shear forces. ${ }^{23-25}$ Ball milling is regarded as an excellent approach that uses shear forces to exfoliate bulk h-BN material down to few-layered sheets. In one study, high-yield and high-quality BNNSs were obtained by low-energy ball milling ${ }^{23}$ and integration of lowenergy ball milling with sonication. ${ }^{26,27}$ Yao et al. ${ }^{26}$ exfoliated h-BN in sodium dodecyl sulfate (SDS)-water solutions into mono- and few-layered BNNSs with a concentration of about $1.2 \mathrm{mg} \mathrm{mL} \mathrm{m}^{-1}$ (Fig. 1). This dispersion exhibited excellent stability (Fig. 1e). All of the aforementioned strategies were performed in liquid media. Some solid media were also reported. ${ }^{28}$

Liquid exfoliation of h-BN was successfully conducted in 1,2dichloroethane solution of poly $(m$-phenyl-enevinylene-co-2,5dictoxy-p-phenylenevinylene), ${ }^{29}$ water, ${ }^{30}$ SDS and water, ${ }^{31} N, N^{\prime}$ dimethylformamide (DMF), ${ }^{32}$ sulfonic acid, and methanesulfonic acid. ${ }^{33}$ To understand the functions of different solvents used in h-BN exfoliation, the Hansen solubility parameter (HSP) theory was proposed by Coleman et al. ${ }^{34}$ The exfoliation effect of the solvents could be verified by polar, hydrogen-bonding, cohesive energy density, which should minimize the energy of exfoliation or with strong, sufficient surface tension (e.g. $\gamma 40 \mathrm{~mJ} \mathrm{~m}{ }^{-2}$ ). With this theory, isopropyl alcohol (IPA) was a good exfoliation agent with a BNNS yield of $\sim 50 \%$ ( $0.06 \mathrm{mg} \mathrm{mL}^{-1}$ BNNS concentration). On the basis of this theory, analyzing the HSP distance and $R_{\mathrm{a}}$ value of diverse solvent mixtures, 55\% ethanol and water solvent were better solvents than IPA that the dispersion concentration was $0.075 \pm$

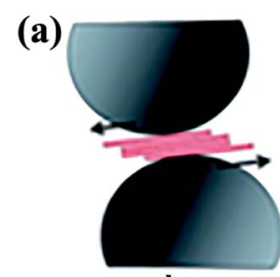

shear

(c)

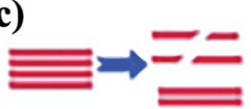

scission (b)

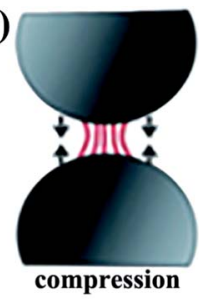

(d)

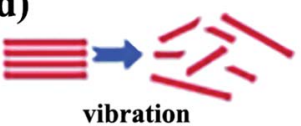

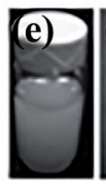
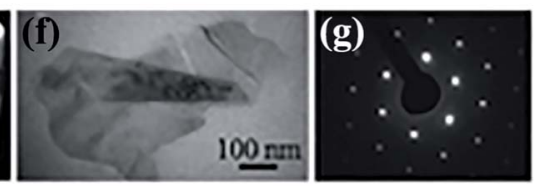

Fig. 1 Exfoliation of 2D nanosheets via low-energy ball milling caused by shear force (a) and compression force (b). Effects of sonicationinduced scission (c) and vibration-induced exfoliation (d) on 2D nanosheets by sonication. (e) Dispersions of BNNSs in SDS-water. (f) Transmission electron microscope (TEM) image of folded BNNSs. (g) Selected area electron diffraction (SAED) observation of BNNSs from the right bottom area of (f). Reproduced with permission from ref. 26.
$0.003 \mathrm{mg} \mathrm{mL}{ }^{-1} \cdot{ }^{35}$ The effect of dispersion is presented in Fig. 2. Subsequently, ammonia solution and IPA were chosen as the exfoliation agents; ammonia molecules could intercalate the hBN layers and thus benefited the exfoliation process. ${ }^{36}$ Given the large surface tension $\left(\gamma=33.3 \mathrm{mN} \mathrm{m}^{-1}\right)$ and small HSP distance $\left(R_{\mathrm{a}}=2.59 \AA\right)$ of thionyl chloride, it could be potentially used to exfoliate and stabilize BNNS dispersions. ${ }^{37}$

Epitaxial growth of monolayer h-BN was achieved on Pt (111) and $\mathrm{Ru}(001)$ substrates via adsorption and decomposition of borazine. ${ }^{38}$ Single-crystalline monolayer h-BN on the Ni (111) substrate with borazine as the precursor was prepared by Oshima et al. ${ }^{39}$ The Ni foil was considered as a preferred substrate because of the minor difference in the lattice constant between the Ni (111) surface (2.49 $⿱$ ) and bulk h-BN (2.5 ̊). Alternatively, B-trichloroborazine (ClBNH) ${ }_{3}$ was found to be a better precursor for monolayer h-BN growth on Pt (111) ${ }^{40}$ and Ni (111). ${ }^{41}$ BNNSs in the form of a so-called nanomesh were synthesized on a $\mathrm{Rh}$ (111) substrate by Corso et $a l^{42}$ The types of substrate influenced the pore shapes and sizes of the nanomesh. ${ }^{43-48}$ A nanomesh could be grown on $\mathrm{Ru}(0001)$ and $\mathrm{Rh}$ (111). However, a flat monolayer h-BN could be grown on Pt (111), Cu (111), Fe (110), Pd (111), Cr (110), Mo (110), and Ni (111). Monolayer and nanomesh h-BN coexisted when Ir (111) was used as the substrate. Monolayer h-BN was grown on a four-inch Rh (111) substrate in a modified ultrahigh vacuum chamber. ${ }^{49}$ This h-BN surface exhibited a corrugated morphology. Similar patterns were observed on an epitaxial h-BN layer measuring 2 in. The wrinkle-free h-BN could be grown on a $c$-plane sapphire substrate measuring 2 in with the $\mathrm{AA}^{\prime}$ stacking order by modified low-pressure chemical vapor deposition (CVD). ${ }^{50}$

$\mathrm{Cu}$ and $\mathrm{Ni}$ foils were traditionally used as substrates for $2 \mathrm{D} \mathrm{h}$ BN growth because of their low-cost and excellent catalytic properties. ${ }^{51,52}$ Typical CVD processes for BNNS growth have used borazine and ammonia borane with $\mathrm{Pt},{ }^{53-55} \mathrm{Ni},{ }^{56,57}$ and $\mathrm{Cu}^{58-63}$ as substrates. Wang et $a{ }^{61}{ }^{61}$ prepared a triangular monolayer single crystal h-BN measuring $20 \mu \mathrm{m}$. This size varied with the thermal annealing time of $\mathrm{Cu}$ foils (Fig. 3). Several catalyst-based substrates, such as heteroepitaxial $\mathrm{Cu}-\mathrm{Ni}$ alloy, ${ }^{64}$ Co film, ${ }^{65}$ and Si-doped Fe substrate, ${ }^{66}$ have been explored. A study found that nanocrystalline graphene could be used as a seed layer for synthesizing large-area h-BN. ${ }^{67}$ In addition, h-BN could be grown on insulating substrates, such as $\mathrm{SiO}_{2} / \mathrm{Si}$ without a catalyst, via microwave plasma CVD. ${ }^{68} \mathrm{Few}^{-}$ layered BNNSs were grown by using a mixture of $\mathrm{B}$, magnesium oxide ( $\mathrm{MgO})$, ferrous oxide ( $\mathrm{FeO}$ ) powders, and ammonia on silica $\left(\mathrm{SiO}_{2}\right) / \mathrm{Si}^{69}$ Wafer-scale multilayer BNNSs were synthesized in vacuum with a subnanometer scale surface roughness. $^{70}$

\section{Fabrication of $\mathrm{h}-\mathrm{BN}$-filled composites}

The processing step exerts significant effects on the bulk properties of composites. Thus, methods of fabricating h-BNfilled composites are briefly reviewed, including solution mixing, melt blending, in situ polymerization, and ball milling. 
(a)

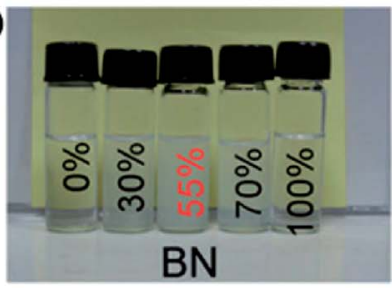

(b) $\uparrow$

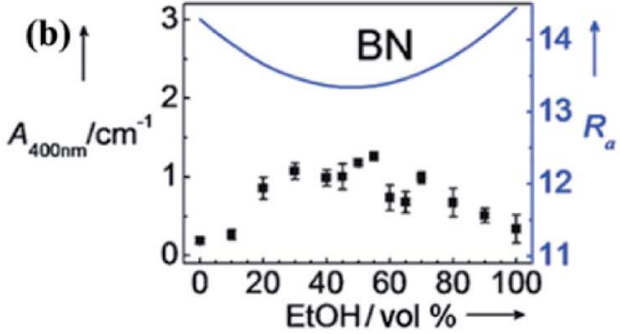

Fig. 2 (a) Photographs of BN dispersions in several ethanol/water mixtures stored under ambient conditions for 1 week. (b) BN suspensions in various ethanol/water mixtures and calculated $R_{\mathrm{a}}$ values are denoted by dots and solid lines, respectively. Reproduced with permission from ref. 35.

\subsection{Solution mixing}

Solution mixing is a facile-operated, commonly used technique for fabricating h-BN-filled polymer composites. A suitable solvent is crucial for the uniform dispersion of h-BN and the polymer matrix, forming metastable suspensions of h-BN or hBN/polymer mixtures. The critical technique during this process involves uniform stirring, which often requires the use of high-power ultrasonication..$^{32}$ Some functionalized strategies, such as heat treatment, ${ }^{71}$ acid treatment ${ }^{72}$ or h-BN functionalization, ${ }^{73-75}$ were conducted to improve the dispersion of h-BN. Many h-BN/polymer composites were successfully prepared by solution mixing, including BN/polymethyl methacrylate (PMMA), ${ }^{32,76}$ BN/poly (vinyl alcohol) (PVA), ${ }^{74,77-79}$ BN/ polybutylene terephthalate (PBT), ${ }^{80}$ BN/epoxy, ${ }^{75,81-83} \quad \mathrm{BN} /$ polyurethane acrylate (PUA), ${ }^{\mathbf{4}}$ and $\mathrm{BN} /$ silicone rubber (SiR). ${ }^{\mathbf{1 4}}$ Song et al. ${ }^{77}$ fabricated BNNS/PVA films by stirring the mixture of aqueous PVA solution and IPA suspension of BNNSs. The solvent was removed with vigorous stirring and then subjected to casting on an etched glass slide, resulting in a thin film with a thermal conductivity higher than $30 \mathrm{~W} \mathrm{~m}^{-1} \mathrm{~K}^{-1}$ (Fig. 4). However, solution mixing is limited to polymers that can be dissolved in solvents which are also suitable for the preparation of a stable suspension of h-BN.

(a)
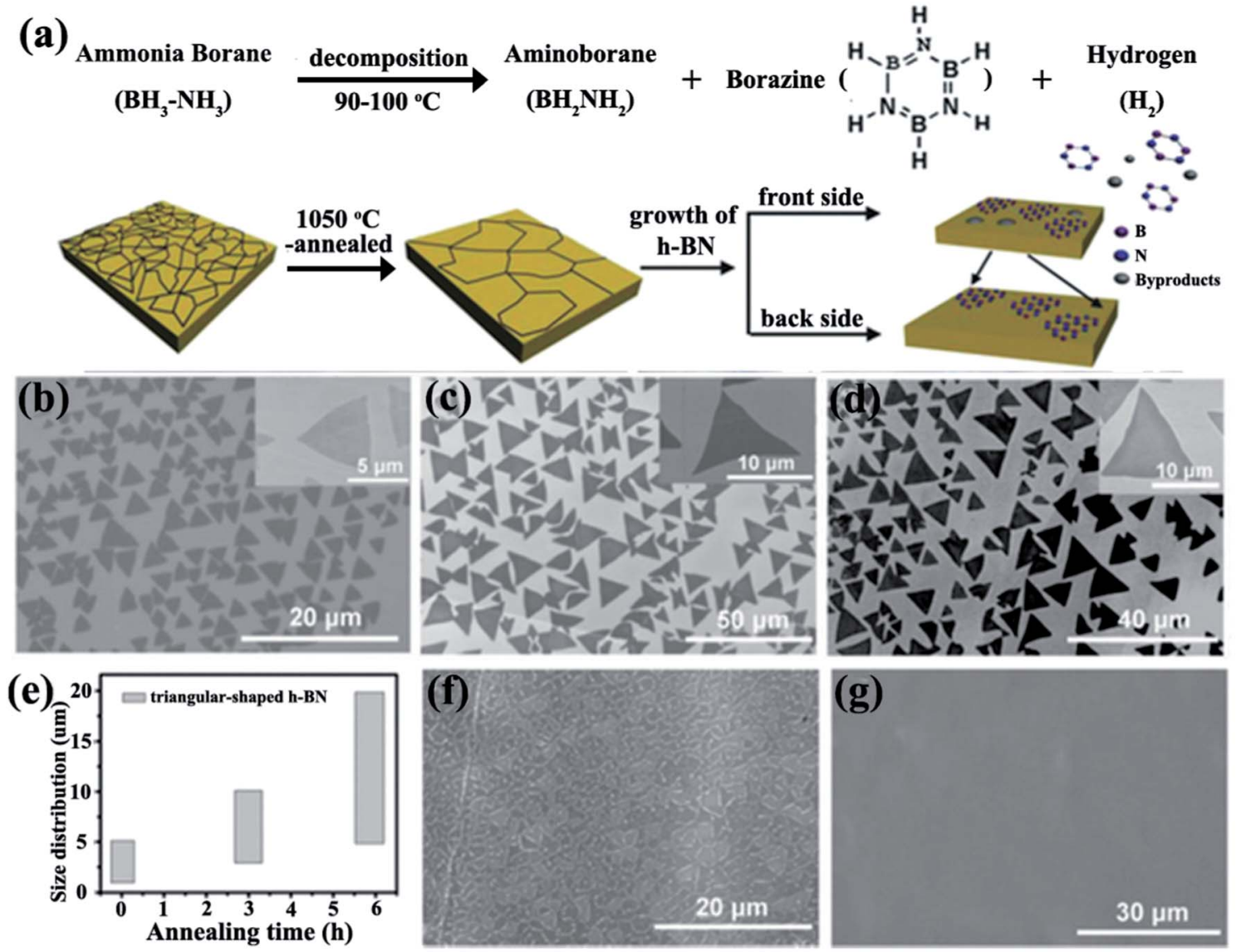

Fig. 3 (a) Dissociation of ammonia borate and $\mathrm{h}$-BN growth. SEM images of $\mathrm{h}$-BN grown without pre-annealing (b) and with annealing for $3 \mathrm{~h}$ (c) and $6 \mathrm{~h}$ (d). (e) Photograph showing variations in the domain size distributions of $\mathrm{h}$-BN with the annealing time of Cu foils. SEM images of $\mathrm{h}$-BN film formed by h-BN domains with growth times of about $65 \mathrm{~min}$ (f) and $70 \mathrm{~min}$ (g). Reproduced with permission from ref. 61. 

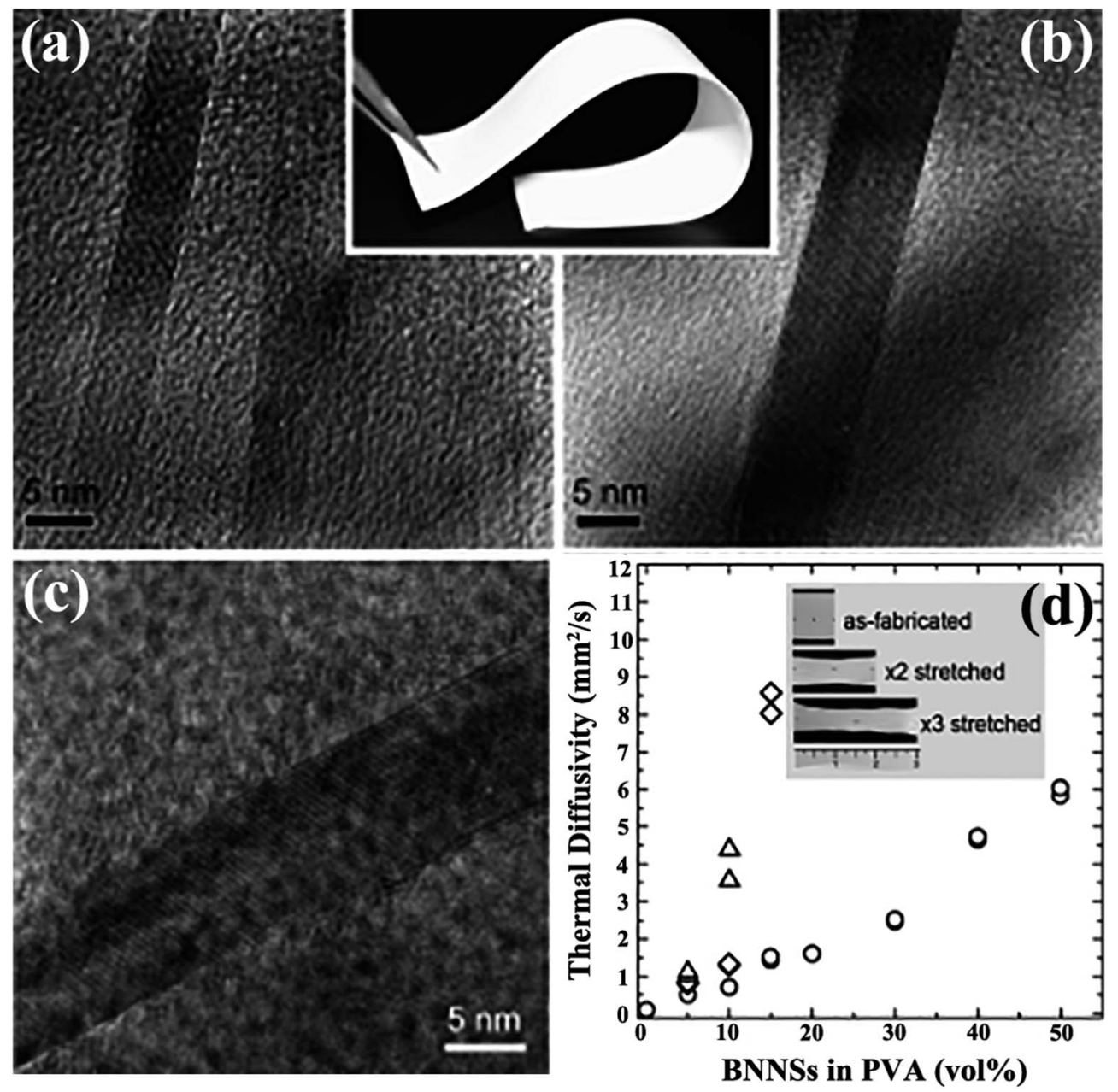

Fig. 4 (a and b) Cross-sectional TEM images of BNNSs/PVA (inset: photograph of a sample). (c) TEM image of BNNSs. (d) Thermal diffusivity of BNNS/PVA films with different BNNS contents. $(O)$ represents the fabricated film, and $(\times 2: \diamond ;$ and $\times 3: \triangle)$ represents mechanically stretched films. Inset: photographs of as-fabricated and stretched films with 10 vol\% BNNS. Reproduced with permission from ref. 77.

\subsection{Melt blending}

Melt blending is a solvent-free process suitable for industrial processes. This technique is usually applied to disperse sheets in a thermoplastic polymer matrix by using high-temperature and high-shear forces. h-BN/bisphenol E cyanate ester (BECy) nanocomposites were fabricated by preheating dopaminetreated h-BN nanoparticles at $130{ }^{\circ} \mathrm{C}$ and then mixing with a BECy resin, followed by curing at $180{ }^{\circ} \mathrm{C}$ and $250{ }^{\circ} \mathrm{C}$ (Fig. 5). ${ }^{73}$ However, melt blending was generally less effective in dispersing sheets in polymers, compared with solution mixing. This approach was limited to low filler loadings because of the high viscosity of the composites at high sheet loadings. Xie et $a .^{85}$ subsequently prepared the mixture of BNNSs with poly(ethylene terephthalate) by melt processing. However, the BNNSs preferred to restack during the drying process. Thus, Guo et $a l .{ }^{86}$ developed a slurry compounding strategy to fabricate BNNS/styrene-butadiene rubber (SBR) composites by using a conventional two-roll mill. The BNNS slurry was prepared using a solvent exchange route. Silane was added to strengthen the interfaces of BNNSs and SBR matrix. Compared with the neat SBR composites, the composites for $10.5 \mathrm{vol} \% \mathrm{Si}-\mathrm{BNNS}$ loading increased the thermal conductivity by $253 \%$.

\subsection{In situ polymerization}

Usually, a high filler loading would sacrifice the mechanical property of the composites. This could be ascribed to the poor stress transfer from matrix to filler caused by agglomeration of fillers. Thus, in situ polymerization was conducted to increase the interface bonding or adhesion between the fillers and polymer matrix. In situ polymerization involves dispersing the reactive monomer into sheet layers, followed by polymerization. ${ }^{87-90}$ This technique allows covalent bonding between functionalized sheets and the polymer matrix via chemical reaction. Distinct composites were prepared using this technique. Styrene was initiated on modified BNNSs by reversible addition-fragmentation chain transfer polymerization to prepare BNNS/polystyrene (PS) composites. ${ }^{87}$ Composites of hBN/PMMA were fabricated by dispersing h-BN particles into methyl methacrylate monomers by bulk polymerization ${ }^{\mathbf{8}}$ and atom transfer radical polymerization. ${ }^{89}$ A typical example was 

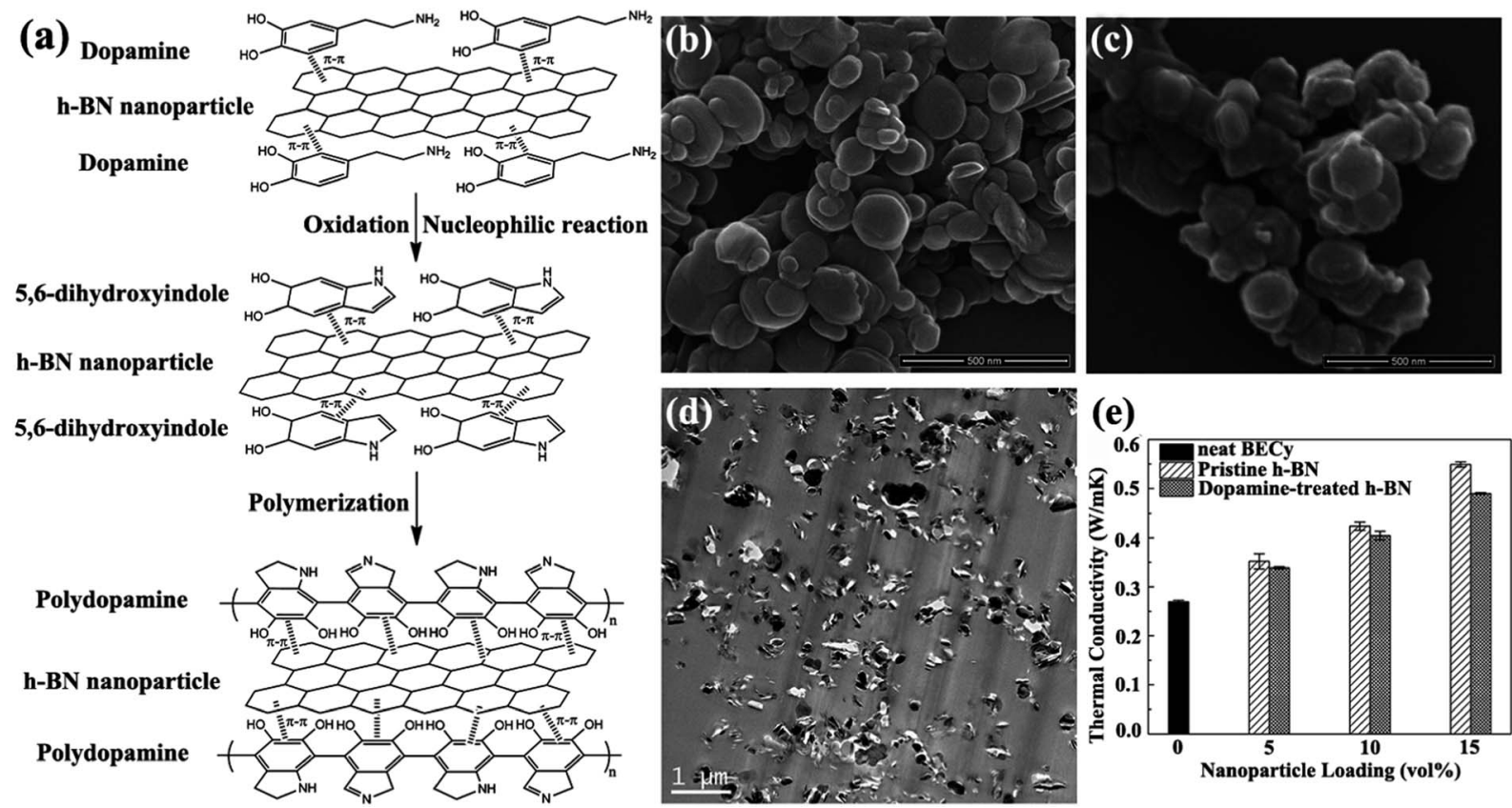

Fig. 5 (a) Illustration of polydopamine functionalized h-BN. SEM observations of h-BN (b) and dopamine-treated h-BN (c). (d) TEM image of hBN/BECy composite with 15 vol\% dopamine-treated h-BN. (e) Variations in the thermal conductivity of h-BN/BECy composite with nanoparticle loadings. Reproduced with permission from ref. 73.

reported by Lee et al..$^{90}$ in which poly(caprolactone) (PCL) was chemically grafted onto BNNSs by oxidized BNNSs (oxi-BNNSs) and subsequent ring-opening polymerization of PCL (Fig. 6). The resulting composites exhibited a thermal conductivity of $1.96 \mathrm{~W} \mathrm{~m}^{-1} \mathrm{~K}^{-1}$ with the incorporation of $20 \mathrm{wt} \%$ BNNSs.

\subsection{Ball milling}

Ball milling is a method of grinding materials into extremely fine powders or dispersions for practical application. The milling balls used are made of different materials, including stainless steel, ceramic, flint pebbles, and so on. High pressure is generated during milling because of the collision of tiny rigid balls in a concealed container. The behavior of powder particles upon milling is generally distinguished into mechanical milling, mechanical alloying, and mechanochemical synthesis. High-energy ball milling presents inherent advantages, such as low cost, versatility, and scalability. Therefore, high-energy ball milling is considered an industrialized technique for manufacturing materials in large quantities. Ball milling on layered materials generates strong shear and compression forces, which can peel off and cleave the materials (Fig. 1). ${ }^{26}$ Thus, ball milling is an excellent approach to reducing the thickness of h-BN. Lee et al. ${ }^{91}$ recently fabricated high-quality and high yield hydroxide BNNSs (OH-BNNSs) with high efficiency by hydroxide-assisted ball milling. The resulting $\mathrm{OH}^{-}$ BNNSs showed little damage, relatively large sheets with an average size of $1.5 \mu \mathrm{m}$, and a high yield of $18 \%$. Functionalized BNNSs (f-BNNSs) were used to fabricate polyethylene composites. Oxygen permeability was reduced by $46 \%$, and water vapor permeability decreased by $34 \%$ with $5 \mathrm{wt} \%$ f-BNNS loading (Fig. 7). Various parameters, such as ball-to-powder ratios, milling speed, milling ball sizes, and milling agents, considered in the preparation of BNNSs in benzyl benzoate were systematically investigated by Chen et al. ${ }^{24}$ The obtained sample had a diameter ranging from $0.5 \mu \mathrm{m}$ to $1.5 \mu \mathrm{m}$ and a yield of $13.8 \%$.

\section{Conducting thermally conductive networks}

The effective routes to assemble fillers in the polymer in order to construct well-organized and interconnected thermally conductive networks are critical for heat transfer. The usual strategies conducted for the construction of thermally conductive networks exhibit alignment, a three-dimensional (3D) network, an interface effect, a hybrid effect, and so on.

\subsection{Alignment}

h-BN is a platelet-shaped particle with a high aspect ratio. In one study, the thermal conductivity of h-BN reached $600 \mathrm{~W} \mathrm{~m}^{-1}$ $\mathrm{K}^{-1}$ in the in-plane direction and $30 \mathrm{~W} \mathrm{~m}^{-1} \mathrm{~K}^{-1}$ in the out-ofplane direction. ${ }^{12}$ Owing to the anisotropic shape and thermal conductivity of h-BN, the arrangement of h-BN in the polymer matrix considerably affected the thermal property of the h-BNfilled composites. Numerous reports recently evaluated the influence of orientation on thermal conductivity enhancement in a preferential direction. The methods used to orient h-BN included processing and external forces.

4.1.1 Alignment during processing. As shear force is introduced by processing methods, such as oscillatory shearing, tape casting, and injection molding, h-BN typically tends to align parallel to the planer direction, as in the case of h-BN oriented in PVA composite films by tape-casting. ${ }^{74}$ The 
(a)

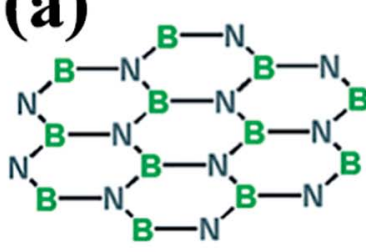<smiles>CC(C)(C)OOC(C)(C)C</smiles>

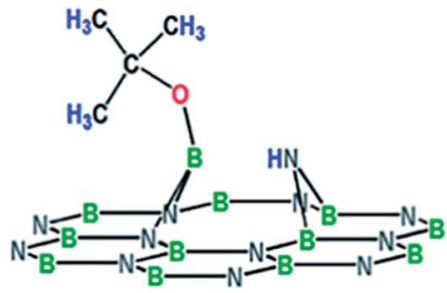

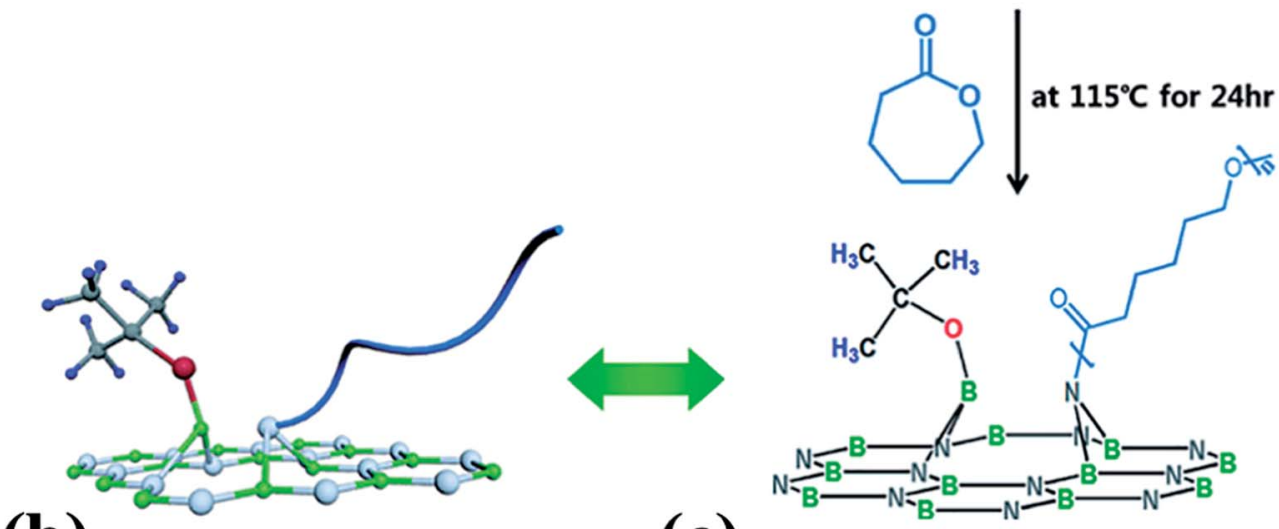

(b)
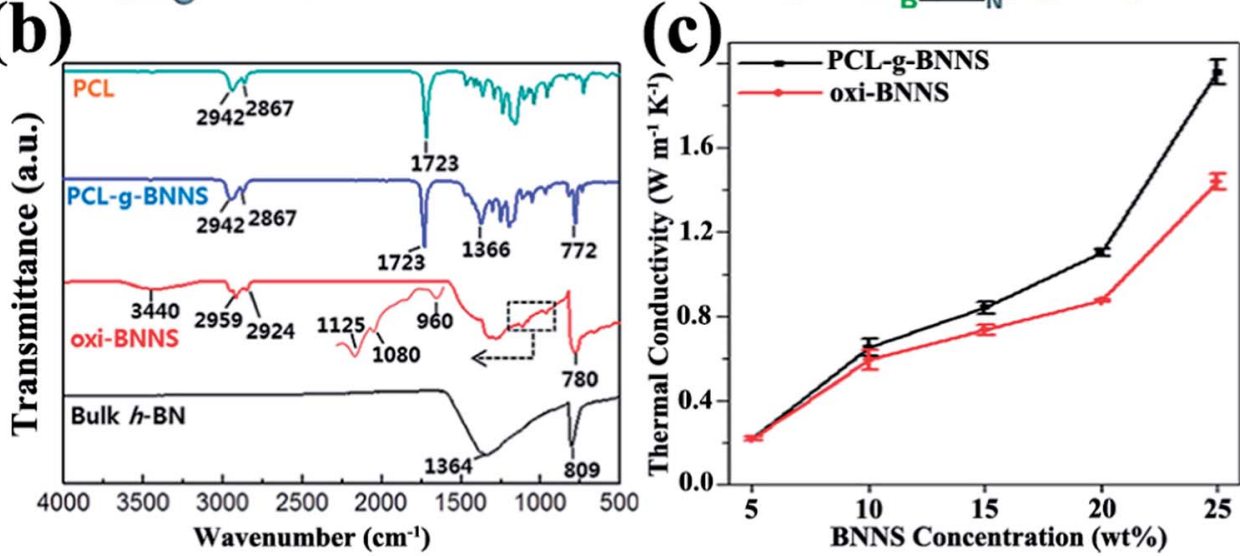
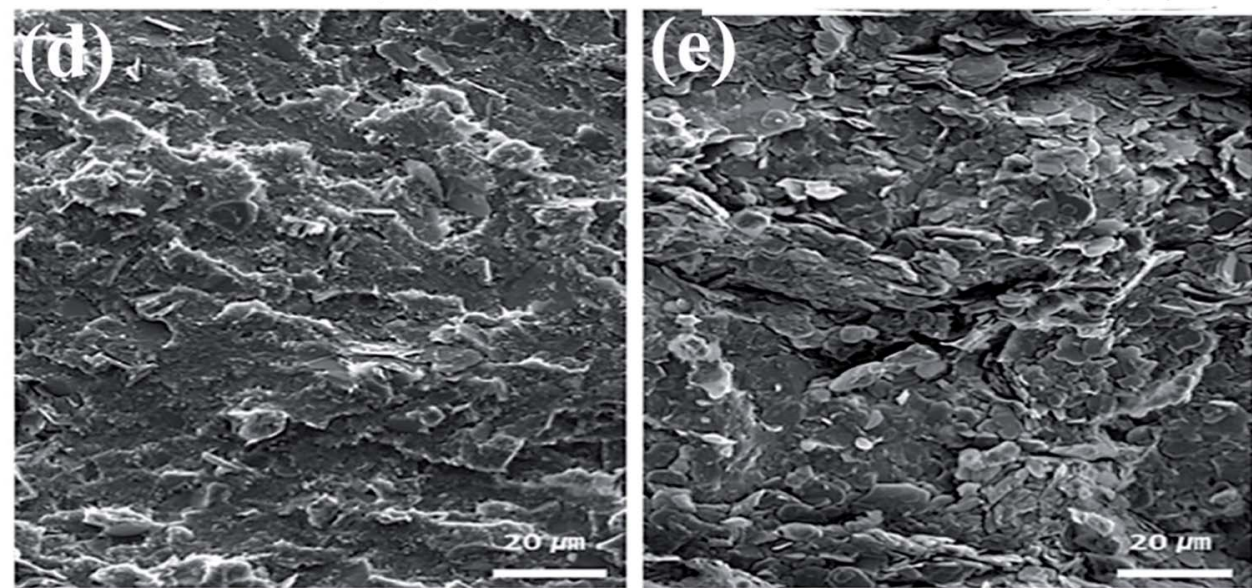

Fig. 6 (a) Fabrication of PCL-g-BNNSs. (b) IR spectra of PCL, PCL-g-BNNSs, oxi-BNNSs, and h-BN. (c) Thermal conductivity of oxi-BNNSs/PCL and PCL-g-BNNSs/PCL composites with BNNS contents. SEM observations of the cross-sectional images of PCL-g-BNNS/PCL (d) and oxiBNNS/PCL (e) composites. Reproduced with permission from ref. 90.

thermal conductivity reached $5.4 \mathrm{~W} \mathrm{~m}^{-1} \mathrm{~K}^{-1}$ for 10 vol\% filler contents. Ceramic particles were oriented in polyvinyl butyral and PVA matrices prepared using a similar method. ${ }^{92,93}$ Kuang et $a .^{14}$ fabricated $\mathrm{BNNS} / \mathrm{SiR}$ and $\mathrm{BNNS} /$ natural rubber $(\mathrm{NR})$ composites with ultrahigh degree of orientation because of strong shear forces introduced by a two-roll mill (Fig. 8). The thermal conductivity of the composites was $\sim 4 \mathrm{~W} \mathrm{~m}^{-1} \mathrm{~K}^{-1}$ with 23 vol\% BNNSs in SiR composites. h-BN/Polypropylene 


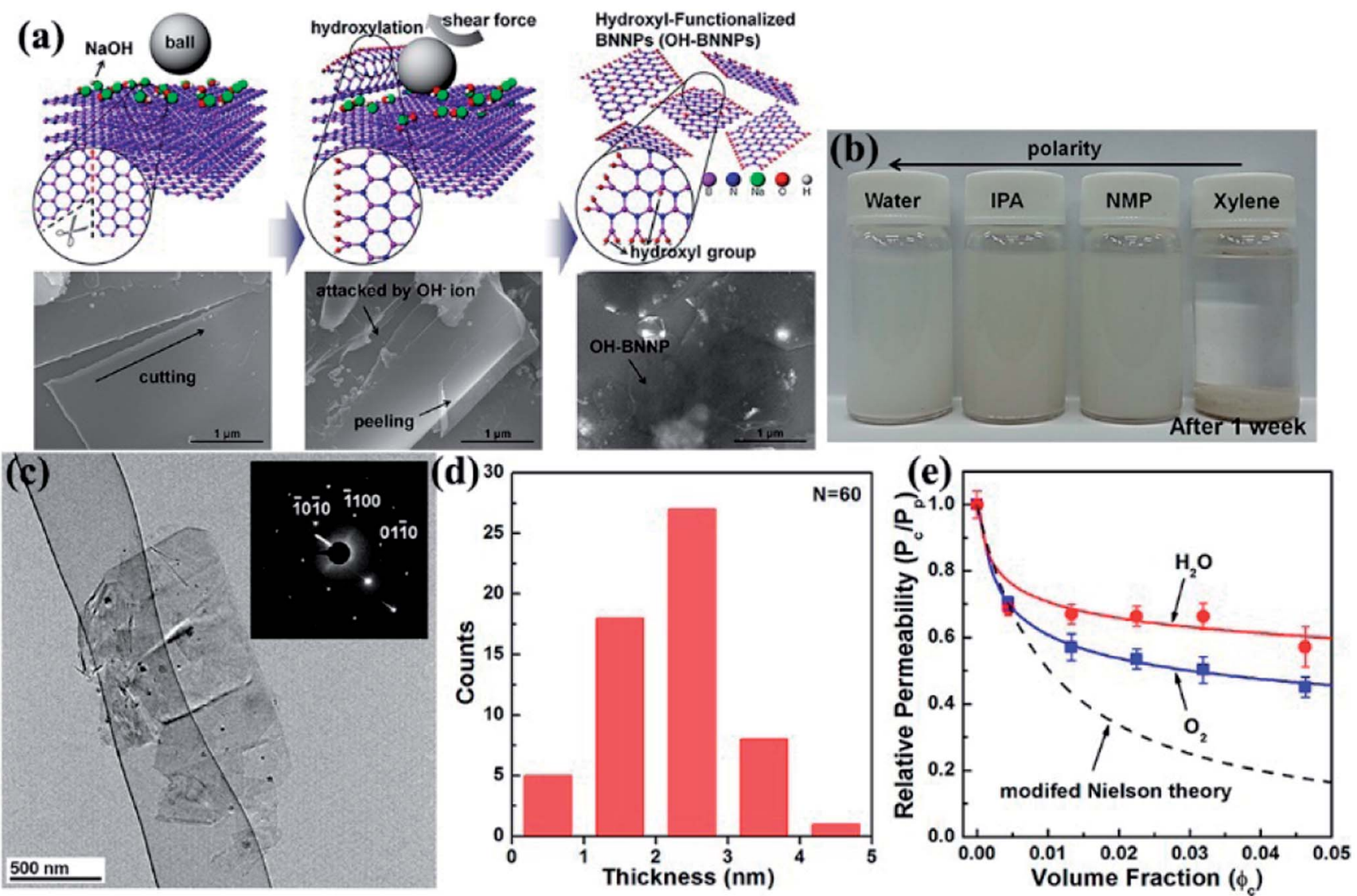

Fig. 7 (a) Schematic and corresponding SEM images of the exfoliation mechanism of $h-B N$. (b) Photographs of OH-BNNS suspensions in different solvents after sonication for 1 week. (c) TEM image of $\mathrm{OH}-$ BNNSs and corresponding SAED patterns. (d) Thickness of 60 platelets. (e) Permeabilities of oxygen and water vapor in composites with varying f-BNNS contents relative to that of the pristine polyethylene film, as well as the values calculated using the modified Nielsen theory. Reproduced with permission from ref. 91.

composites with a high degree of orientation were obtained by injection molding. ${ }^{94}$ The corresponding thermal conductivity showed a large increase, which reached $2.1 \mathrm{~W} \mathrm{~m}^{-1} \mathrm{~K}^{-1}$ with the incorporation of $40 \mathrm{vol} \% \mathrm{~h}-\mathrm{BN}$.

4.1.2 Alignment by external fields. Alignment of h-BN in composites can be achieved by applying a suitable external field, such as magnetic, electric, and gravitational force fields.

4.1.2.1 Magnetic field alignment. Studart et al. ${ }^{95}$ proposed in 2012 an approach to align anisotropic reinforcing microparticles in the composite matrix by applying external magnetic fields. This proposal prompted a discussion among numerous researchers on thermal conductivity enhancement of h-BNbased composites by magnetic field-induced alignment. Reinforcing particles are often diamagnetic; as such, they were first coated with superparamagnetic nanoparticles. The filler arrangement in low-viscosity suspending fluids was controlled using a low external magnetic field. h-BN complex sheets modified with iron oxide nanoparticles were successfully rearranged in the direction vertical to the film plane in the study by Cho et al., ${ }^{96}$ as shown in Fig. 9. Thus, iron oxide-coated h-BN filled epoxy composites exhibited excellent thermal properties. $^{12,13,97}$ The highest thermal conductivity obtained was $4.7 \mathrm{~W}$ $\mathrm{m}^{-1} \mathrm{~K}^{-1}$ at $20 \mathrm{vol} \%$ iron oxide-coated h-BN for an epoxy resin system..$^{13}$ Luo et al. ${ }^{98}$ used a similar method to fabricate iron oxide-coated h-BN/SiR composites. The thermal conductivity of the composites was $44.5 \%$ higher than that of the unaligned composites with 9.14 vol\% filler loading. A theoretical model was used to analyze the results, suggesting that the orientation of the BNNSs mainly led to the improvement of thermal conductivity. CVD was also conducted to deposit iron oxide onto BNNSs. The obtained modified BNNSs were successfully oriented in the polysiloxane matrix with a magnetic field (Fig. 9). ${ }^{96}$

4.1.2.2 Electric field alignment. BNNSs can be oriented by an extra electric field. BNNSs/polysiloxane composites were fabricated under a dc electric field (Fig. 10). ${ }^{99}$ BNNSs in the matrix are reoriented in the electric field direction. This direction can be controlled to be perpendicular to the film plane. Fieldinduced orientation of BNNSs in the polysiloxane matrix was successfully accomplished. ${ }^{100}$

4.1.2.3 Gravitational force-induced alignment. Gravitational force is preferred to align BNNSs in the in-plane direction. This strategy was facile, simple, and resulted in a high degree of orientation. The highest thermal conductivity reported in h-BNfilled composites was $145.7 \mathrm{~W} \mathrm{~m}^{-1} \mathrm{~K}^{-1}$ at $50 \mathrm{wt} \% \mathrm{~h}-\mathrm{BN}$ content, which was ascribed to the constitution of hierarchically 
(a)
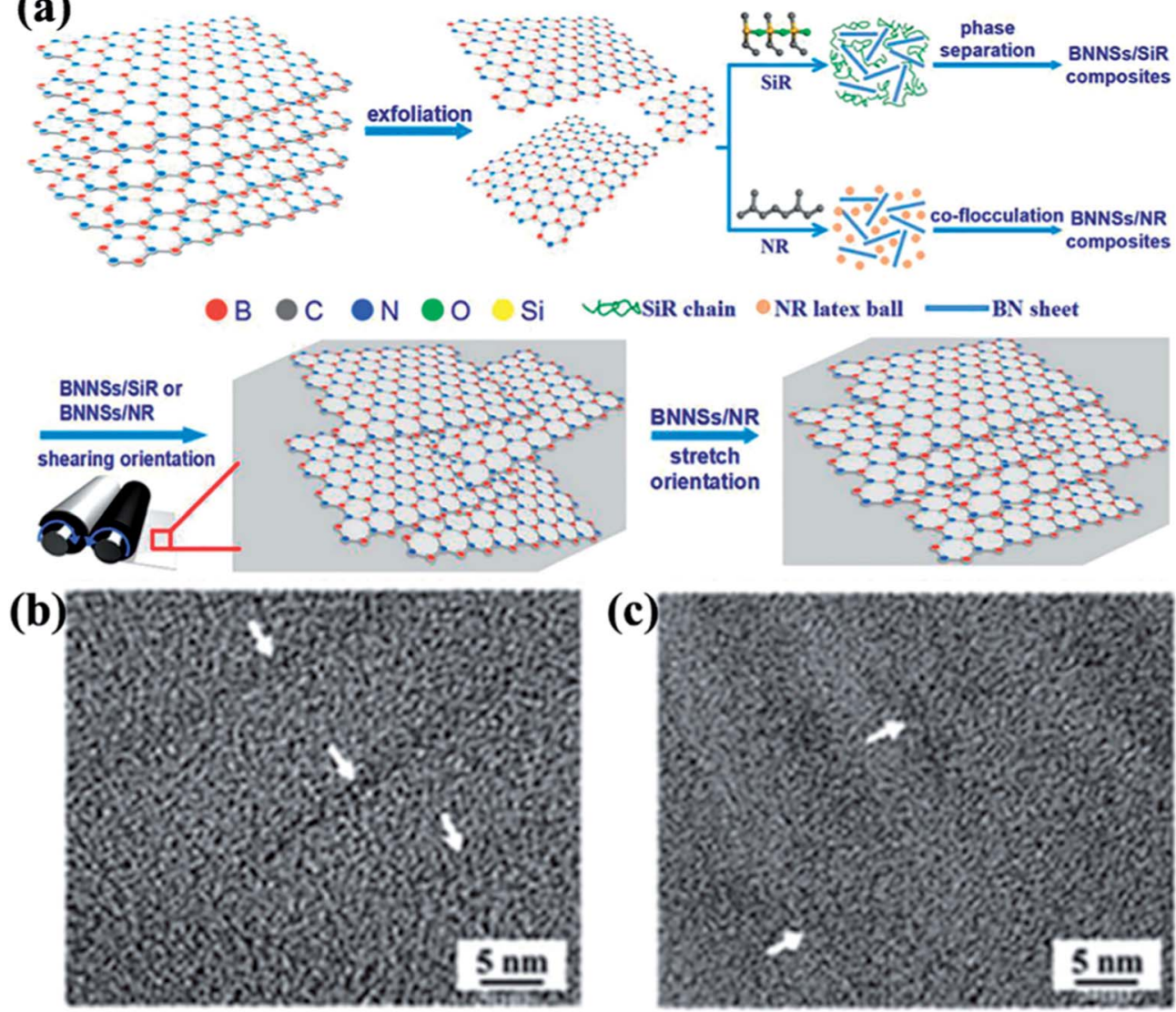

(d)

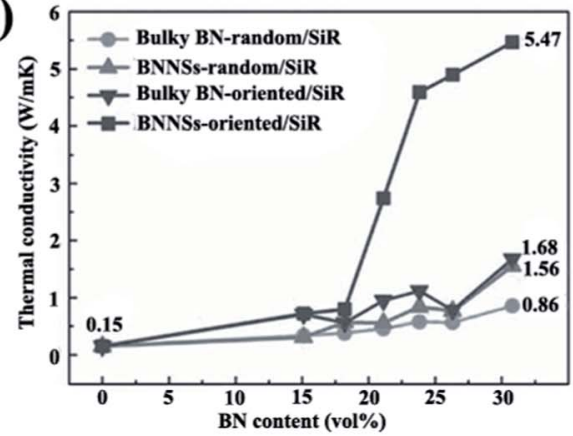

(c)

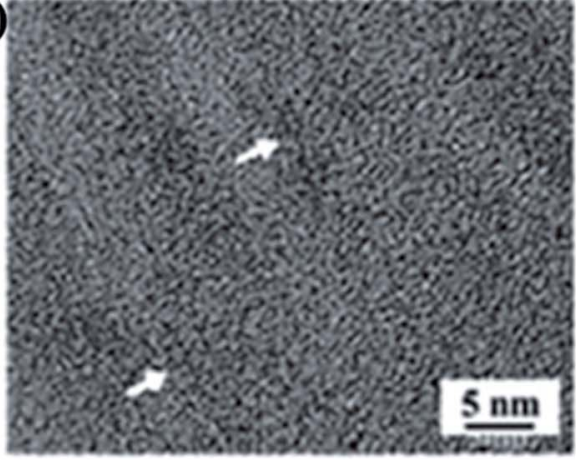

(e)

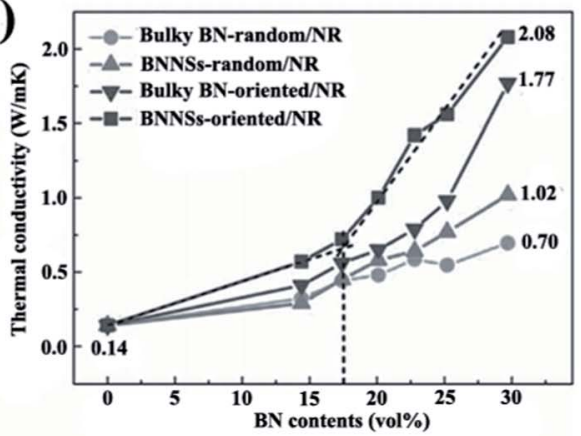

Fig. 8 (a) Preparation of BNNS/SiR and BNNS/NR composites. High-resolution TEM images of BNNS/SiR (b) and BNNS/NR (c) composites with 4 vol\% BNNS loadings. Thermal conductivities of BNNS/SiR (d) and BNNS/NR (e) composites with different BNNS contents. Reproduced with permission from ref. 14.

arranged 2D BNNSs and 1-dimensional (1D) cellulose formed during vacuum-assisted filtration. ${ }^{\mathbf{1 0 1}}$ A large contact area was formed between BNNSs in this structure, thereby minimizing the influence of interface thermal resistance along the thermally conductive direction. An orderly oriented structure based on cellulose nanofibers (CNFs) and f-BNNSs was prepared by simple vacuum-assisted filtration with superior thermal conductivity of up to $30.25 \mathrm{~W} \mathrm{~m}^{-1} \mathrm{~K}^{-1}$ with the incorporation of $70 \mathrm{wt} \%$ f-BNNS (Fig. 11). ${ }^{102}$ In addition, pure laminates of h-BN could be prepared by vacuum filtration of the h-BN dispersion prepared via liquid exfoliation in IPA. ${ }^{\mathbf{1 0 3}}$ The thermal conductivity of such insulating laminates reached $20 \mathrm{~W} \mathrm{~m}^{-1} \mathrm{~K}^{-1}$. By improving the quality of the flake-to-flake interface, the interface thermal resistance decreased and thus enhanced thermal conductivity. OH-BNNSs could be obtained by molten alkaliassisted exfoliation of h-BN, which improved the interfacial bonding strength between BNNS layers. ${ }^{\mathbf{1 0 4}}$ Subsequent filtration resulted in $\mathrm{OH}-\mathrm{BNNS}$ papers with superior thermal conductivity of $58 \mathrm{~W} \mathrm{~m}^{-1} \mathrm{~K}^{-1}$. The traditional platelet filler contents in the polymer composites were lower than $40 \mathrm{wt} \%$. However, a high filler loading can be achieved by vacuum-assisted filtration. Composite paper analogous to artificial nacre consisting of noncovalent functionalized BNNSs (NF-BNNSs) and PVA with ultrahigh filler loading of $94 \mathrm{wt} \%$ was fabricated by vacuum- 

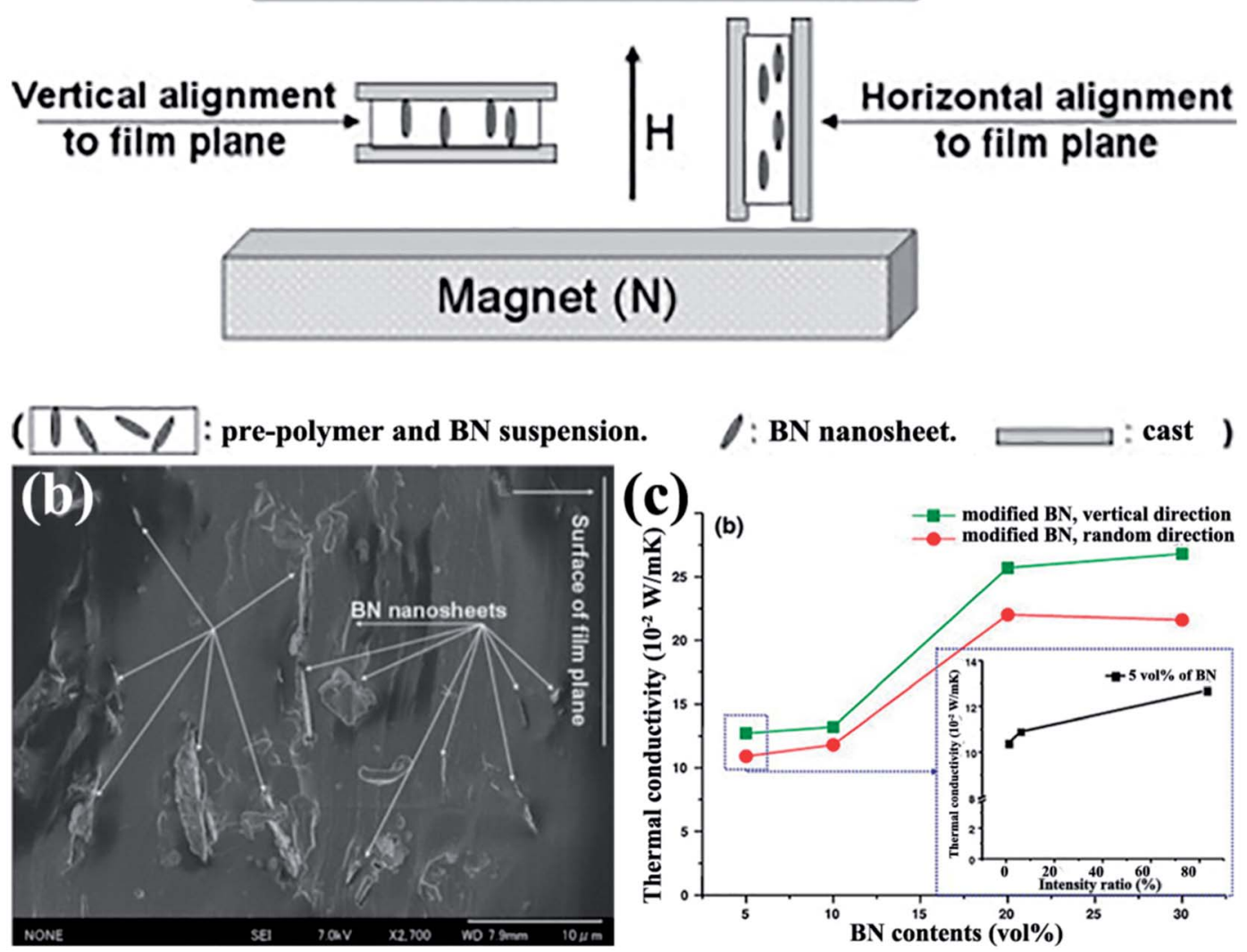

Fig. 9 (a) Illustration of experimental setups. (b) Fracture images of polysiloxane composites at 5 vol\% BN loading with horizontal alignment. (c) Variations in the thermal conductivity of BNNS/polysiloxane composite films with BNNS loadings (inset: variations in the thermal conductivity of composites with 5 vol\% BN content as a function of intensity ratio). Reproduced with permission from ref. 96.

induced filtration. ${ }^{78} \mathrm{~A}$ framework constructed by hierarchically arranged BNNSs and PVA was formed by gravitational force. This paper exhibited high thermal conductivity of $6.9 \mathrm{~W} \mathrm{~m}^{-1}$ $\mathrm{K}^{-1}$.

\subsection{D networks}

Isotropic thermally conductive bulk composites are favorable to a certain extent in some applications. Thus, forming threedimensional (3D) networks with high quality and low thermal resistance for heat conduction present a significant challenge. Up to now, the commonly strategy used to construct 3D networks was to form thermally conductive networks firstly and then infiltrating with polymer. Thus, the thermal performance of the composites improved a lot at only a low filler loading. The thermal conductivity enhancement efficiency of 3D network composites to pure polymer matrix was expressed by thermal conductivity enhancement per 1 vol\% loading $(\eta),{ }^{105}$ which was defined as $\eta=\left(K-K_{\mathrm{m}}\right) \times 100 \% /\left(100 \times V K_{\mathrm{m}}\right)$, where $K$ and $K_{\mathrm{m}}$ represented the thermal conductivity of the composites and polymer matrix, respectively. And $V$ represented the volume contents of h-BN in composites. As shown in Fig. 12, CNFsupported 3D-interconnected BNNS (3D-C-BNNS) aerogels were fabricated by self-assembly of BNNSs on a 3D cellulose skeleton via sol-gel and freeze-drying. ${ }^{106}$ Composites exhibiting high thermal conductivity were then prepared by impregnating epoxy resin into the 3D BNNS aerogel. Ultrahigh thermal conductivity of $3.13 \mathrm{~W} \mathrm{~m}^{-1} \mathrm{~K}^{-1}$ was achieved at a low BNNS loading level of $9.6 \mathrm{vol} \%$, which corresponded to a thermal conductivity enhancement of about $1400 \%$. In addition, the thermal conductivity enhancement could be easily adjusted by tailoring the BNNS loadings in the interconnected 3D network.

An ice-templated approach was reported to construct 3D BNNS networks (Fig. 13). ${ }^{105}$ This strategy obtained epoxy composites with high thermal conductivity $\left(2.85 \mathrm{~W} \mathrm{~m}^{-1} \mathrm{~K}^{-1}\right)$ at a relatively low filler content (9.29 vol\%). Yang et al. ${ }^{107}$ subsequently used a similar method to fabricate graphene oxide (GO)/ h-BN hybrid porous scaffolds by introducing polyethylene glycol and obtained thermal conductivity of $1.84 \mathrm{~W} \mathrm{~m}^{-1} \mathrm{~K}^{-1}$ at $19.2 \mathrm{wt} \% \mathrm{~h}-\mathrm{BN}$.

\subsection{Interface effect}

A large body of evidence supports the finding that surface modification can reduce interface thermal resistance. For chemical surface modification, covalent bonding or 

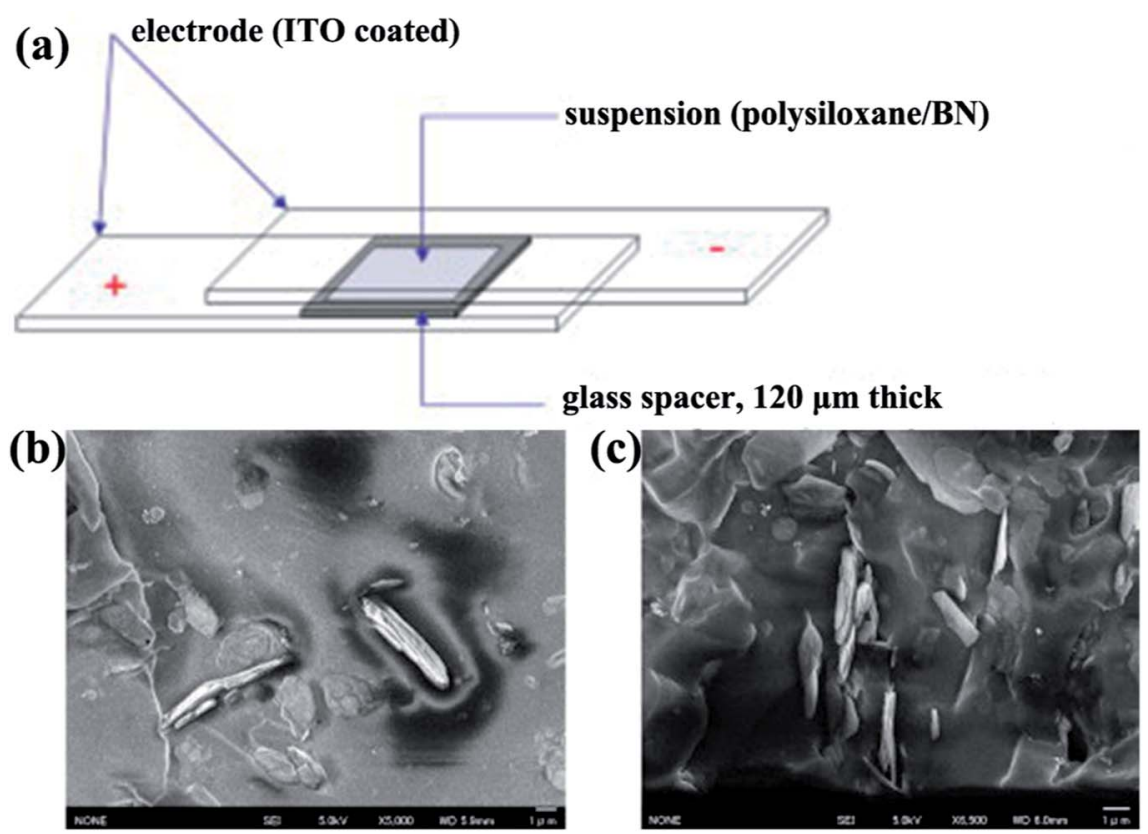

Fig. 10 (a) Illustration of the experimental setup for the fabrication of aligned BN/polymer films. Cross-sectional SEM micrographs of an oriented BN/polysiloxane composite at 10 vol\% BN content without (b) and with (c) the application of electric fields. Reproduced with permission from ref. 99.

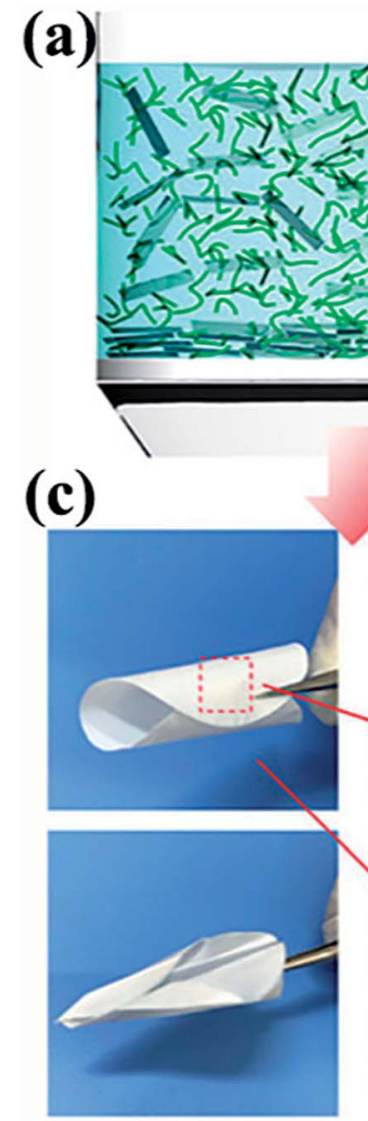

(b)
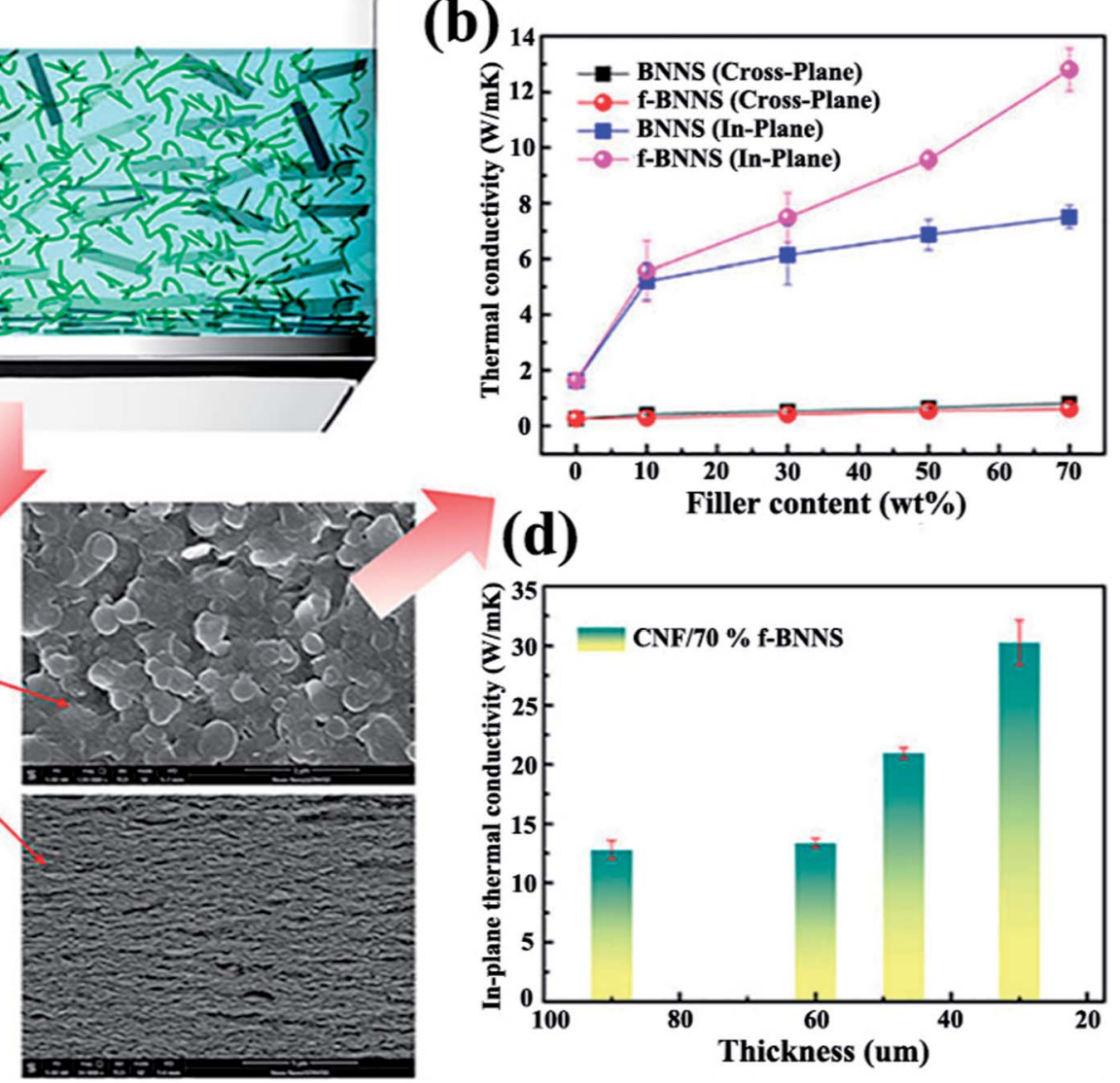

(d)

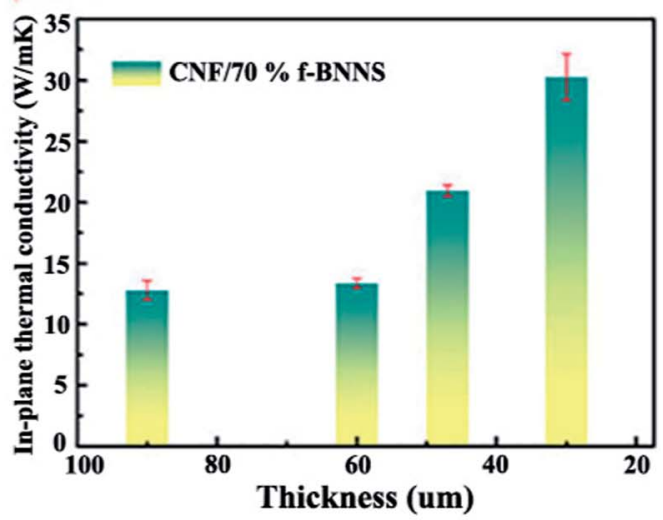

Fig. 11 (a) Demonstration of BNNSs or f-BNNSs in CNF aqueous solution during vacuum-assisted filtration. (b) Thermal conductivity of CNF composite films. (c) Photographs of CNF/BNNS and CNF/f-BNNS films with 70 wt\% BNNS loadings and the corresponding SEM images. (d) Inplane thermal conductivity of CNF/f-BNNS films at $70 \mathrm{wt} \%$ filler contents with different thicknesses. Reproduced with permission from ref. 102. 

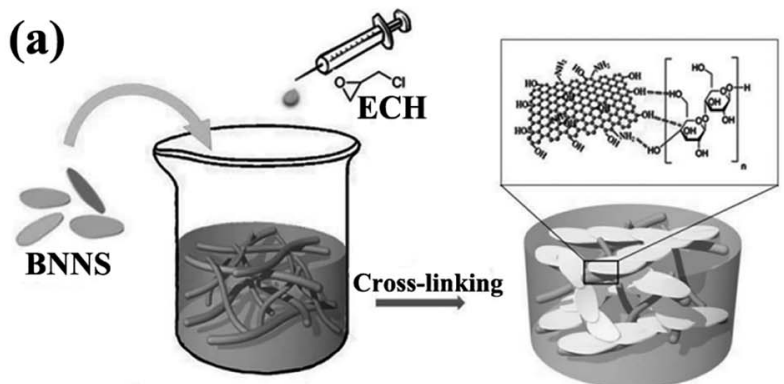

$\mathrm{NaOH} /$ urea/cellulose gel

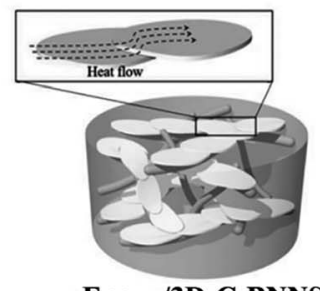

3D-C-BNNS hydrogel
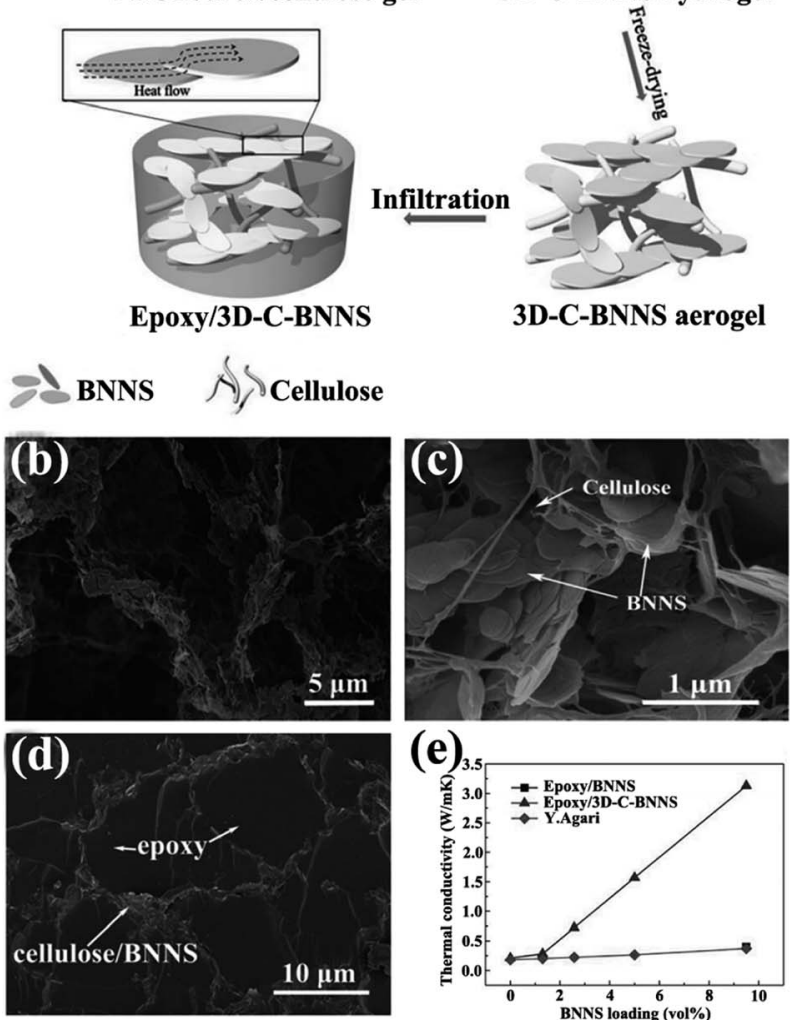

(e)

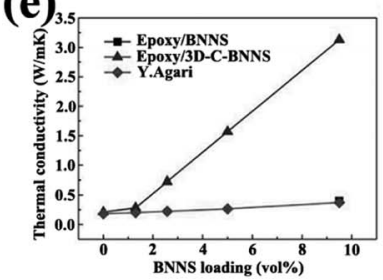

Fig. 12 (a) Preparation of epoxy/3D-C-BNNS composites. SEM views of 3D-C-BNNS aerogel with 5 vol\% (b) and 9.6 vol\% (c) BNNSs. (d) SEM image of the cross-sectional structure of epoxy/3D-C-BNNS composites with 9.6 vol\% BNNS loading. (e) Thermal conductivity of composite variations with BNNS loadings. Reproduced with permission from ref. 106.

noncovalent bonding are the commonly used methods to connect the polymer matrix and fillers.

4.3.1 Covalent modification. Covalent functionalization of BNNSs requires the formation of covalent bonds on the basal plane of the BNNS lattice. Attributed to the partial ionic characteristic of B-N bonds in an h-BN structure, its B atom bore a partially positive charge, whereas the $\mathrm{N}$ atom bore a negative charge. This characteristic exposed $\mathrm{B}$ and $\mathrm{N}$ sites to attacks by nucleophilic and electrophilic groups, respectively.

Several studies have thus far been reported on the production of $\mathrm{OH}-\mathrm{BNNSs}$ and subsequent $\mathrm{OH}-\mathrm{BNNSs} /$ polymer composites with enhanced thermal performance. In 2013, $30 \%$ hydrogen peroxide was used to treat h-BN powders in an autoclave at $100{ }^{\circ} \mathrm{C} .{ }^{108}$ The functionalization of h-BN was found to have improved the compatibility among fillers and the matrix, resulting in a high thermal conductivity of $3.92 \mathrm{~W} \mathrm{~m}^{-1}$ $\mathrm{K}^{-1}$ at $10 \mathrm{wt} \% \mathrm{~h}-\mathrm{BN}$ loadings in the PVA matrix. Tang et al. ${ }^{109}$ employed a mixed solution of concentrated sulfuric acid $\left(\mathrm{H}_{2} \mathrm{SO}_{4}\right)$ and nitric acid $\left(\mathrm{HNO}_{3}\right)$ to synthesize acid-treated BNNSs to enhance the thermal performance of epoxy composites. Thus, the thermal conductivity channel of the obtained composites was first constructed at $5.05 \mathrm{wt} \%$, which was higher than that of pure BNNS-epoxy composites at $6.10 \mathrm{wt} \%$. These methods were based on a liquid medium, which was difficult to remove completely because of their high boiling points. Therefore, a 1-step route in the preparation of OH-BNNS was developed by Huang et $a .^{71}$ by which h-BN could be directly exfoliated at a high temperature of $850{ }^{\circ} \mathrm{C}$ (Fig. 14). The resulting $\mathrm{OH}-\mathrm{BNNSs}$ exhibited excellent dispersibility in water (concentration of $0.3 \mathrm{mg} \mathrm{mL}^{-1}$ ) and ethanol (concentration of $0.06 \mathrm{mg} \mathrm{mL}^{-1}$ ), rendering the $\mathrm{OH}-\mathrm{BNNSs}$ effective as a hydrogel additive. The $\mathrm{OH}-\mathrm{BNNS} /$ poly$(N$-isopropylacrylamide) (PNIPAM) hydrogel composite showed a $41 \%$ increase in thermal conductivity at $0.07 \mathrm{wt} \% \mathrm{OH}-\mathrm{BNNS}$. In addition, $\mathrm{Xu}$ et $a .^{72}$ treated h-BN with acetone, $\mathrm{HNO}_{3}, \mathrm{H}_{2} \mathrm{SO}_{4}$, and silane, showing varying levels of effectiveness in enhancing thermal conductivity. The results exhibited that surface treatment using silane Z-6040 (2.4\%) was most effective for h-BN. The thermal conductivity reached $10.3 \mathrm{~W} \mathrm{~m}^{-1} \mathrm{~K}^{-1}$ at 57 vol\% h-BN loading. The introduced -OH groups improved the interface compatibility; thus, the diffuse path of phonon was opened between BNNSs and the polymer matrix, leading to increased thermal conductivity.

The $\mathrm{OH}-\mathrm{BN}$ or $\mathrm{NH}_{2}-\mathrm{BN}$ typically served as the initiators in the design of many complex h-BN derivatives. The obtained h$\mathrm{BN}$ derivatives were used as fillers to enhance the interface adhesion between h-BN and the polymer matrix, leading to a higher dispersion of platelets in polymers and enhancing the thermal performance. To enhance the affinity of the BNNS/ polymer interface, a hyperbranched polyamide (HBP) was attached to the modified BNNSs. The HBP was formed by introducing amino groups to the surface of BNNSs and then initiating HBP growth (Fig. 15). ${ }^{75,82}$ The obtained epoxy composites exhibited a thermal conductivity of $9.81 \mathrm{~W} \mathrm{~m}^{-1} \mathrm{~K}^{-1}$ with 50 vol\% BNNSs. Kim et al. ${ }^{\mathbf{8 1 , 8 4 , 1 1 0}}$ conducted studies on grafting silane coupling agents onto the h-BN surface for a high thermal performance. The common strategy was to attach a hydroxyl group onto the h-BN surface by using sodium hydroxide at a high temperature, followed by grafting silane coupling agents, such as 3-(glycidoxypropyl)trimethoxysilane, 3chloropropyltrimethoxysilane, ${ }^{\mathbf{8 1 , 1 1 0}}$ and 3-aminopropyltriethoxy silane, ${ }^{84}$ to modify the surfaces, which was a smart route to reduce interface thermal resistance. The chemical reagents used in these strategies were not environmentally friendly, and solvent removal entailed difficulty. Consequently, a solvent-free method was developed by Zhi et al. ${ }^{111}$ to fabricate epoxy composites. The h-BN powder was treated with KH550, a silane coupling agent, followed by mixing with a solid-state epoxy resin. This strategy was suitable for nearly any filler fraction. The maximum thermal conductivity reached $5.24 \mathrm{~W} \mathrm{~m}^{-1} \mathrm{~K}^{-1}$. 

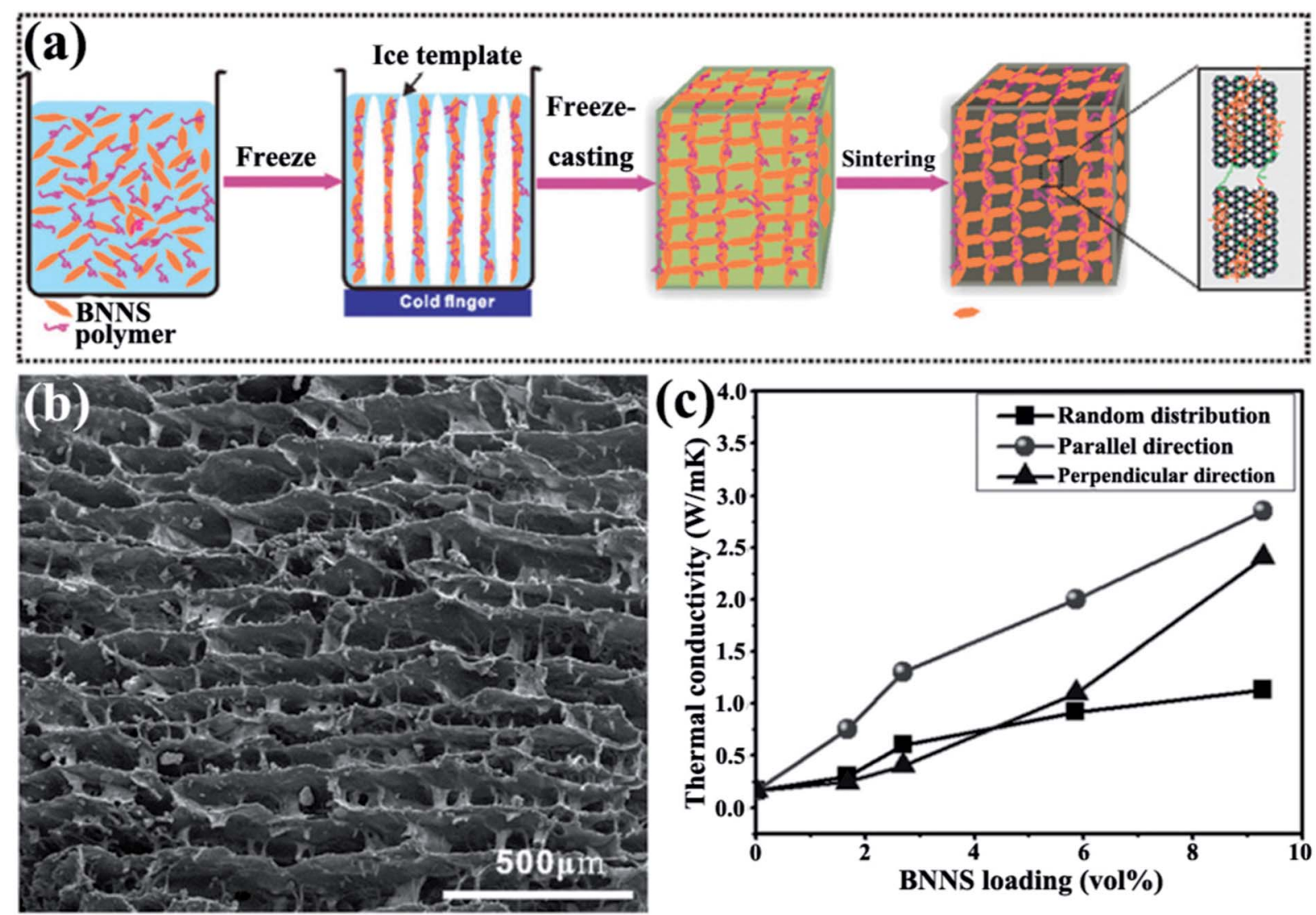

Fig. 13 (a) Preparation of 3D-BNNS/epoxy composites. (b) SEM image of 3D-BNNS aerogel with a density of $195.2 \mathrm{mg} \mathrm{cm}^{-3}$ in the vertical direction to ice growth. (c) Thermal conductivity of composite variations with BNNS loadings. Reproduced with permission from ref. 105.

4.3.2 Noncovalent modification. Noncovalent bonding is a facile method to modify the surface without introducing defects on the surface of BNNSs. Noncovalent modification was the technique employed to physically adsorb polymer on the surface of BNNSs. Thus, the crystallinity of noncovalent functionalized BNNSs was perfectly maintained even after treatment while interfacial adhesion between BNNSs and the matrix increased. Therefore, the thermal conductivity of the composites was enhanced.

Owing to its superior adhesive ability, polydopamine (PDA) was typically applied to modify the surface of h-BN. Xu et al. ${ }^{74}$ adopted dopamine chemistry to coat a thickness of about $4 \mathrm{~nm}$ PDA on the h-BN surface (Fig. 16). The thermal conductivity of h-BN@PDA/PVA composites was about $5.4 \mathrm{~W} \mathrm{~m}^{-1} \mathrm{~K}^{-1}$ with the addition of 10 vol\% h-BN@PDA. Meanwhile, Kessler et al. ${ }^{73}$ used a similar method to prepare h-BN@PDA/BECy composites and achieved a lower thermal performance of $0.5 \mathrm{~W} \mathrm{~m}^{-1}$ $\mathrm{K}^{-1}$ for a 15 vol\% filler loading. In addition, chlorosulfonic acid (CSA) exhibited strong physical adsorption on h-BN surfaces. $^{80}$ The physical adsorption of CSA provided high solubility for BNNSs in various organic solvents and thermoplastic polymers, yielding NF-BNNS/PBT composite films with enhanced through-plane thermal conductivity of up to $11.0 \mathrm{~W}$ $\mathrm{m}^{-1} \mathrm{~K}^{-1}$.

\subsection{Hybrid effect}

The simultaneous use of fillers with different shapes and types was an alternative strategy to enhance the thermal performance of composites.

4.4.1 Morphology and size effect. The effects of 11 artificially designed filler shapes on the thermal conductivity of the composite materials were evaluated. ${ }^{112}$ The results indicated that the best fillers have long heat transfer distances and continuously large contact areas. Double Y-shaped fillers were considered preferable to other fillers, whereas spherical fillers were considered the worst. In addition to shape, hybrid sizes can influence thermal performance because large h-BN has a longer heat transfer distance than that of small h-BN. The large h-BN contributed more to the thermal conductivity of the material. The small h-BN could bridge the distances between h-BN crystals to increase contact. ${ }^{113,114}$ Hybrid h-BN with $M_{0.3 \mu \mathrm{m}}: M_{6 \mu \mathrm{m}}: M_{20} \mu \mathrm{m}$ at a mass ratio of $1: 1: 2$ in a total of 40 vol\% leads to a higher thermal conductivity of $1.482 \mathrm{~W} \mathrm{~m}^{-1} \mathrm{~K}^{-1}$ in SiR composites than that of $50 \mathrm{vol} \% \mathrm{BN}_{6} \mu \mathrm{m}$ with a thermal conductivity of $1 \mathrm{~W} \mathrm{~m}^{-1} \mathrm{~K}^{-1} \cdot{ }^{115}$ Subsequently, microsized and nanosized $\mathrm{BN}$ were combined to prepare polyimide (PI) films. ${ }^{116}$ The obtained sample filled with $30 \mathrm{wt} \%$ h-BN (microsize : nanosized = 7:3 wt $\%$ ) obtained a thermal conductivity of up to $1.2 \mathrm{~W} \mathrm{~m}^{-1} \mathrm{~K}^{-1}$. This value was higher than that obtained using pure microsized BN. These enhancements in thermal property were attributed to the high 

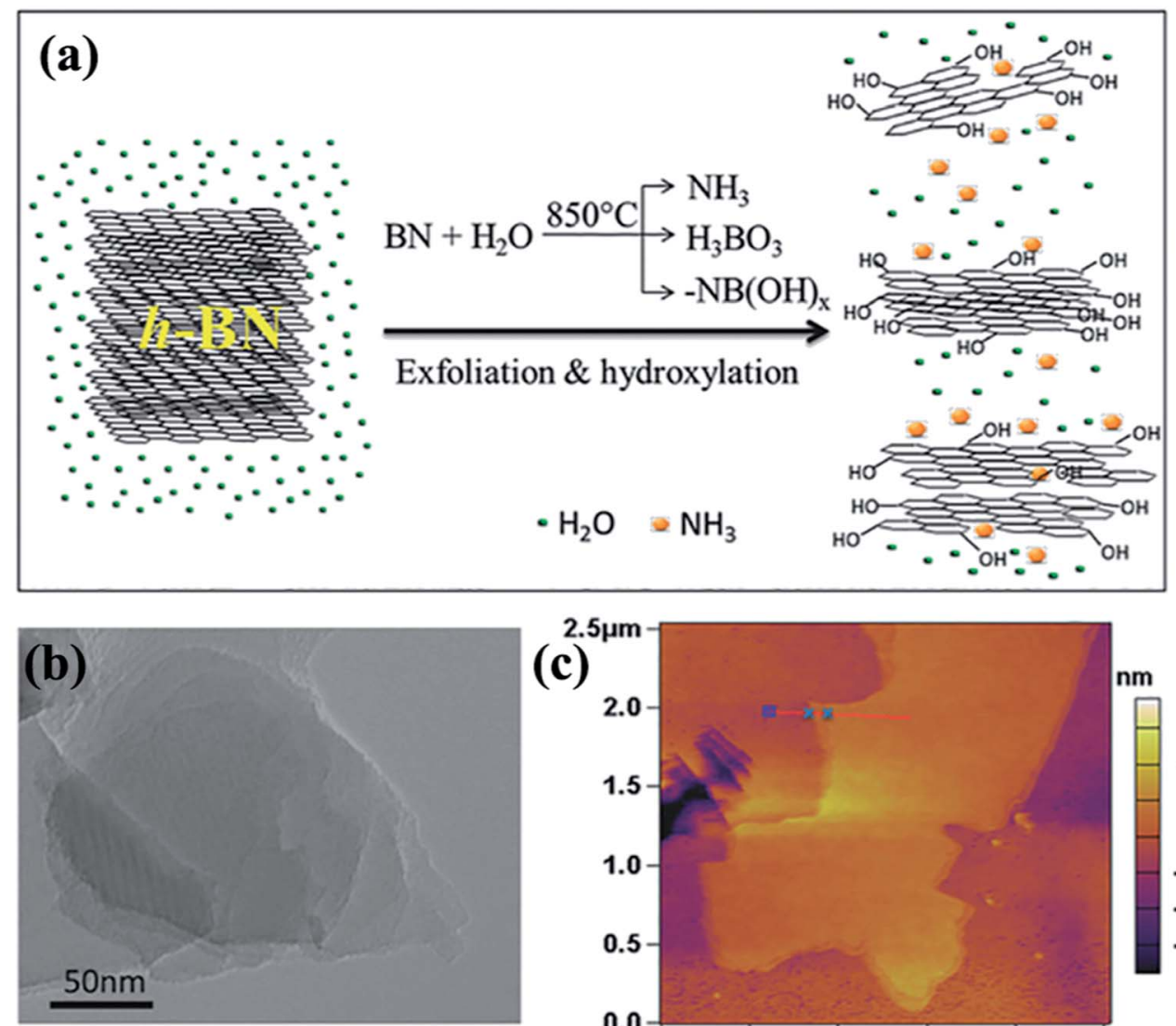

(c)
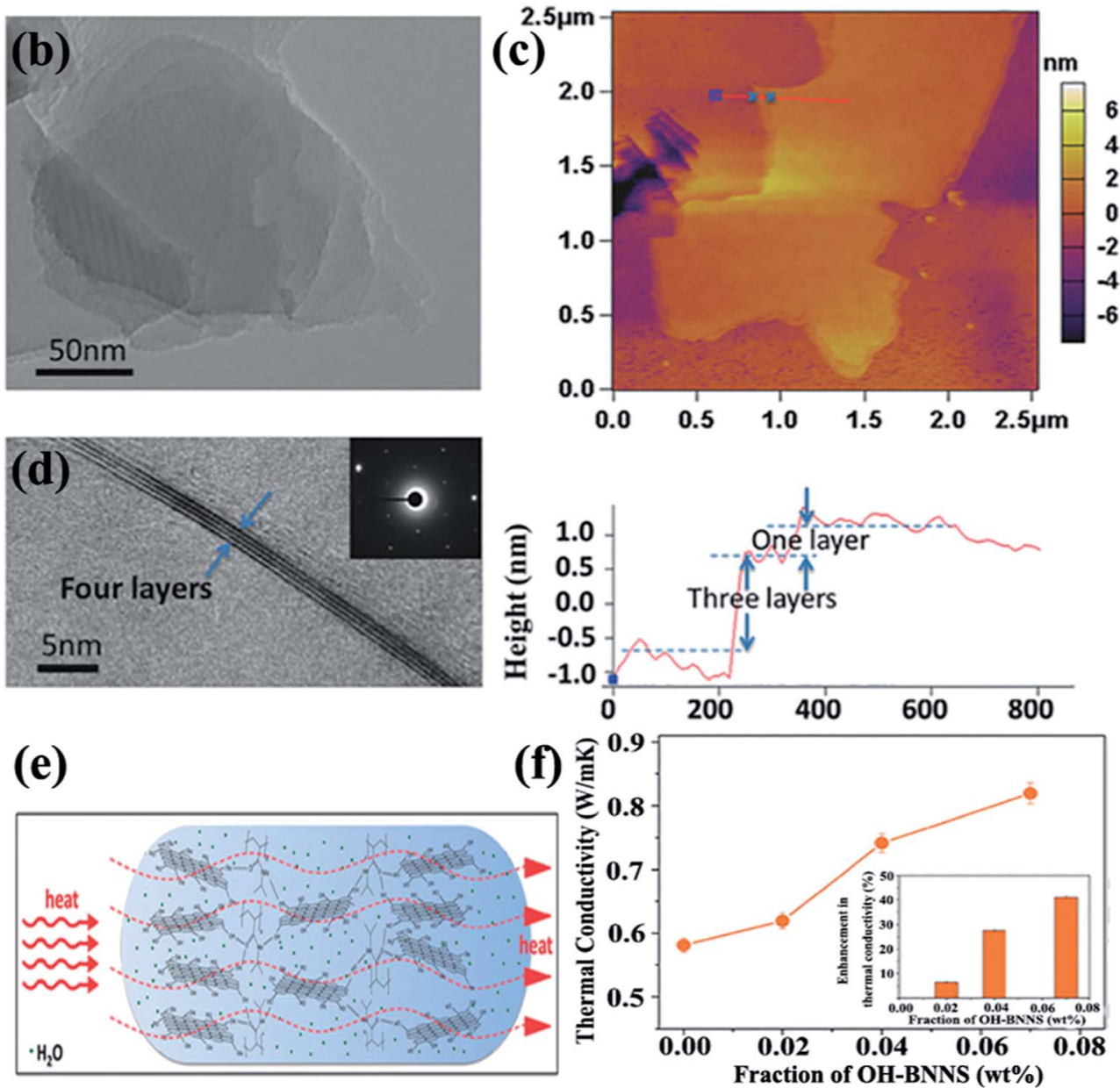

Fig. 14 (a) Exfoliation and hydroxylation of $\mathrm{h}-\mathrm{BN}$. (b) TEM image showing a Moiré patterns. (c) AFM observation showing OH-BNNSs and corresponding height profiles. (d) TEM image showing few-layered OH-BNNSs and the corresponding SAED. (e) Heat transfer in OH-BNNS/ PNIPAM hydrogel. (f) Thermal conductivity variations of hydrogels with $\mathrm{OH}-\mathrm{BNNS}$ (inset: percentages of thermal enhancement). Reproduced with permission from ref. 71

packing density and ease of formation of heat transfer pathways. The studies mainly discussed the effects exerted by microsized BN, whereas those by nanosized BN were rarely reported. Thus, Kemaloglu et al. ${ }^{\mathbf{1 1 7}}$ used 3 micro-size and 2 nanosized h-BN with different particle sizes and shapes in SiR composites. The results showed that nanosized $\mathrm{BN}$ could not promote the thermal conductivity as much as the microsize $\mathrm{BN}$. A plate-like particle with an aspect ratio of 20 was believed to exhibit the highest thermal performance. 


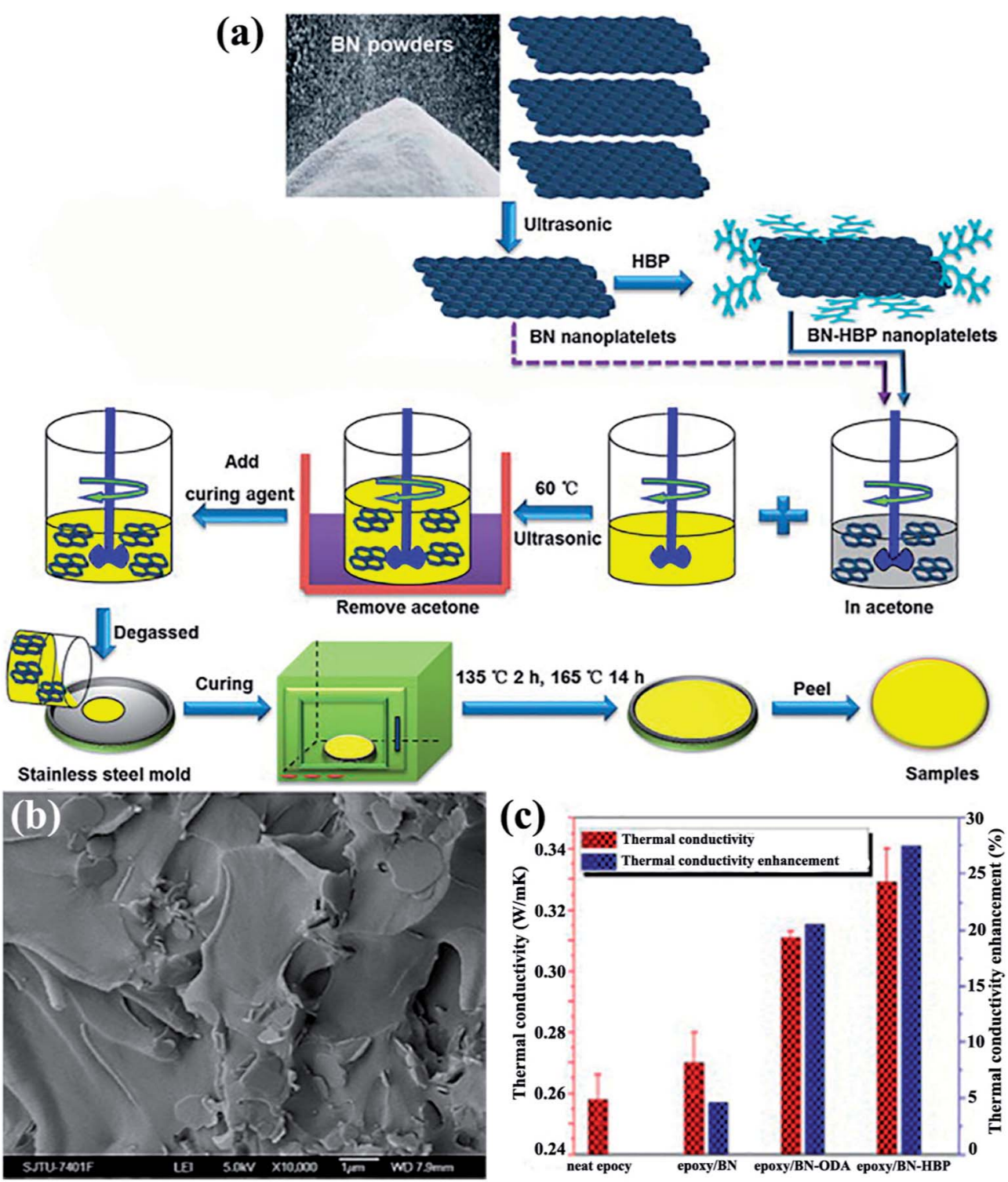

Fig. 15 (a) Preparation of the epoxy composites. (b) Cross-sectional SEM image of the epoxy/BN-HBP composite surface. (c) Thermal conductivity and the corresponding enhancements of the composites at $100{ }^{\circ} \mathrm{C}$. Reproduced with permission from ref. 75 .

4.4.2 h-BN/nanoparticle-filled composites. Interfacial thermal resistance is regarded as the main factor influencing the thermal performance of composites, which arises from poor mechanical or chemical adherence at interfaces. The aforementioned strategies were related to the reduction in filler/ matrix resistance. However, studies on the filler/filler interface have rarely been reported. Jiang et al. ${ }^{118}$ used $\alpha$-alumina $(\alpha$ $\mathrm{Al}_{2} \mathrm{O}_{3}$ ) to bridge BNNSs to construct more compactible 3D thermally conductive networks, resulting in more heat transfer pathways in the composites. The obtained sample exhibited a thermal conductivity of $0.808 \mathrm{~W} \mathrm{~m}^{-1} \mathrm{~K}^{-1}$ at $26.5 \mathrm{vol} \%$ filler loading. Permal et al. ${ }^{\mathbf{1 1 9}}$ recently combined polygonal $\mathrm{Al}_{2} \mathrm{O}_{3}$ and $\mathrm{BN}$ to improve the thermal performance of epoxy composites, which reached $0.57 \mathrm{~W} \mathrm{~m}^{-1} \mathrm{~K}^{-1}$ with the addition of a $30 \mathrm{wt} \%$ filler $\left(\mathrm{Al}_{2} \mathrm{O}_{3}: \mathrm{BN}_{1} \mu \mathrm{m}=5: 5\right)$. Layer-shaped fillers were more favorable than the ball-shaped or sharp-corner-shaped fillers in improving the thermal performance of epoxy resins. ${ }^{\mathbf{1 2 0}}$ However, the thermal conductivity remained low because of the absence of contact between $\mathrm{Al}_{2} \mathrm{O}_{3}$ and BNNSs. Silver nanoparticles (AgNPs) could be sintered together during epoxy curing and acted as "solders" to link BNNSs. AgNP-deposited BNNSs (BNNSs/AgNPs) were used as fillers for the epoxy matrix and provided a higher thermal conductivity of $3.06 \mathrm{~W}$ $\mathrm{m}^{-1} \mathrm{~K}^{-1}$ with 25.1 vol\% BNNS loading. ${ }^{121}$ However, the obtained thermal conductivity remained lower than $5 \mathrm{~W} \mathrm{~m}^{-1} \mathrm{~K}^{-1}$. Thus, silicon carbide nanowires (SiCNWs) were introduced to enhance the thermal performance of PVA composites. ${ }^{\mathbf{1 2 2}}$ Bioinspired BNNS-AgNP/SiCNW-AgNP/PVA composite papers were fabricated and exhibited a superior thermal conductivity of about $21.7 \mathrm{~W} \mathrm{~m}^{-1} \mathrm{~K}^{-1}$. The preparation process is illustrated in Fig. 17. 
(a)

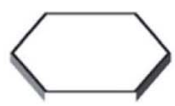

h-BN

Tris buffer: ethanol $=3: 1$ RT
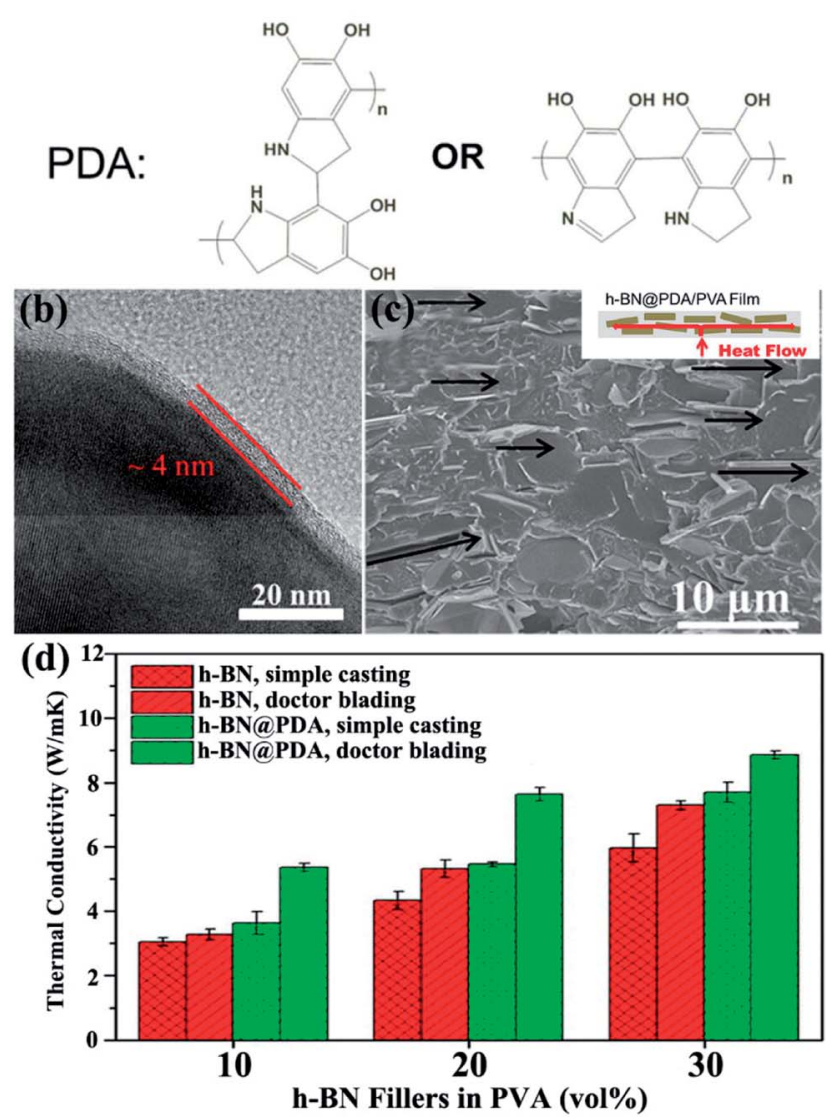

Fig. 16 (a) Process of dopamine chemistry. (b) TEM image of $h$ BN@PDA microplatelets. (c) Fracture SEM image of the h-BN@PDA composite film with 20 vol\% h-BN contents prepared by doctor blading. (d) Thermal conductivity of the fabricated composite films. Reproduced with permission from ref. 74 .

4.4.3 h-BN/carbon material-filled composite. To enhance the affinity between fillers and the polymer matrix, the common route was to modify the surface of the fillers. Carbon materials, such as graphene and carbon nanotubes (CNTs), and h-BN were combined as a mixed filler to improve the thermal performance of the polymer matrix. The mixed fillers were found to exert a synergistic effect on the thermal enhancement of the composites. When coupling agent-functionalized BN (f-BN) was combined with glycidyl methacrylate-grafted graphene ( $\mathrm{g}-\mathrm{TrG})$ and then added into the PI matrix, the voids between BN and the PI matrix were filled by the graphene nanolayers. ${ }^{123}$ The process is illustrated in Fig. 18. The resulting composites containing additional $1 \mathrm{wt} \% \mathrm{~g}$-TrG exhibited a thermal conductivity of $2.11 \mathrm{~W} \mathrm{~m}^{-1} \mathrm{~K}^{-1}$, which was at least doubled to the value of $\mathrm{f}$ BN/PI. The graphene content in the mixed fillers was smaller. Meanwhile, when the BN content was smaller, the nanosized (a) $\mathrm{h}-\mathrm{BN}$
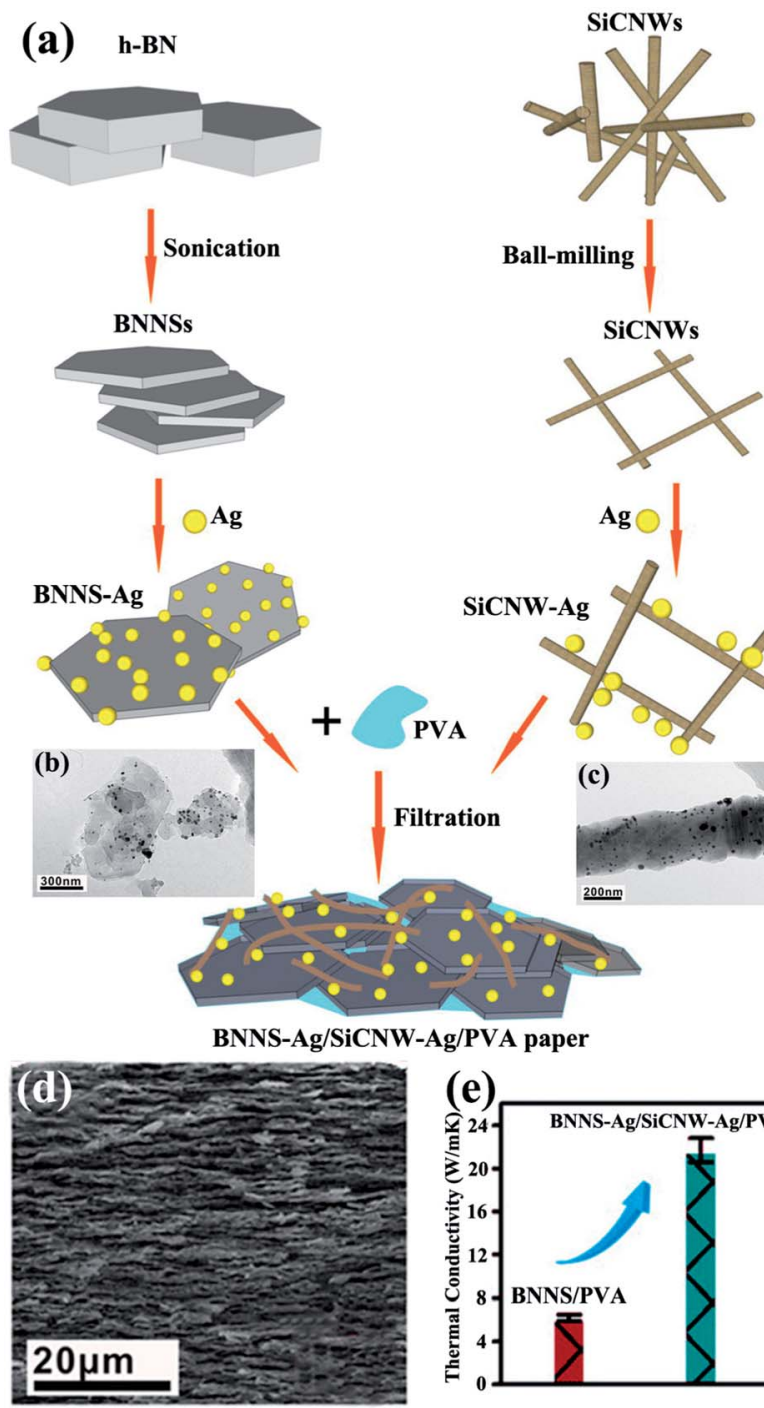

Ball-milling

SiCNWs

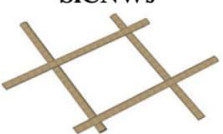

PVA

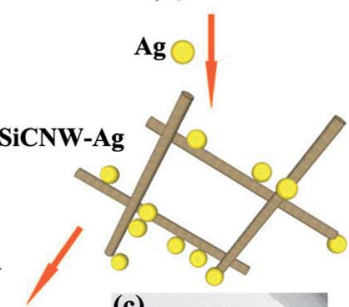

(c)

(c)

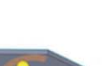

$\underline{200 \mathrm{~nm}}$

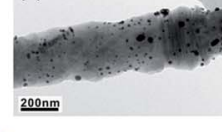

Fig. 17 (a) Fabrication of BNNS-Ag/SiCNW-Ag/PVA paper. TEM images of BNNS-Ag (b) and SiCNW-Ag (c). (d) Fracture SEM observation of BNNS-Ag/SiCNW-Ag/PVA paper. (e) Thermal conductivity of BNNS/PVA and BNNS-Ag/SiCNW-Ag/PVA papers. Reproduced with permission from ref. 122.

BN was filled into the graphene interspaces and thus formed a BN/graphene stacked structure, markedly enhancing the thermal conductivity. ${ }^{124}$ Additional $1.5 \mathrm{wt} \% \mathrm{~h}-\mathrm{BN}$ could increase the thermal conductivity to $38 \%$ and $34 \%$ in PS and polyamide 6 (PA 6) matrix, respectively. The previously described fillers were based on 2D platelets. Once the 1D and 2D fillers were mixed, a hybrid 3D filler network structure could be formed. Thus, a small amount of CNTs ( $2 \mathrm{wt} \%$ ) was introduced into the BNfilled poly(vinylidene fluoride) (PVDF) composites. ${ }^{125}$ The results showed that the addition of CNTs to the BN/PVDF composites facilitated the formation of a denser 3D BN/CNT network structure. The thermal conductivity of $1.3 \mathrm{~W} \mathrm{~m}^{-1} \mathrm{~K}^{-1}$ at $22 \mathrm{wt} \%$ filler loading ( $2 \mathrm{wt} \%$ CNTs and $20 \mathrm{wt} \% \mathrm{BN}$ ) was thus enhanced. This thermal conductivity was higher than that of PVDF $/ 20 \mathrm{wt} \% \mathrm{BN}\left(0.97 \mathrm{~W} \mathrm{~m}^{-1} \mathrm{~K}^{-1}\right)$ and PVDF $/ 2 \mathrm{wt} \%$ CNTs $\left(0.28 \mathrm{~W} \mathrm{~m}^{-1} \mathrm{~K}^{-1}\right)$. 
(a)

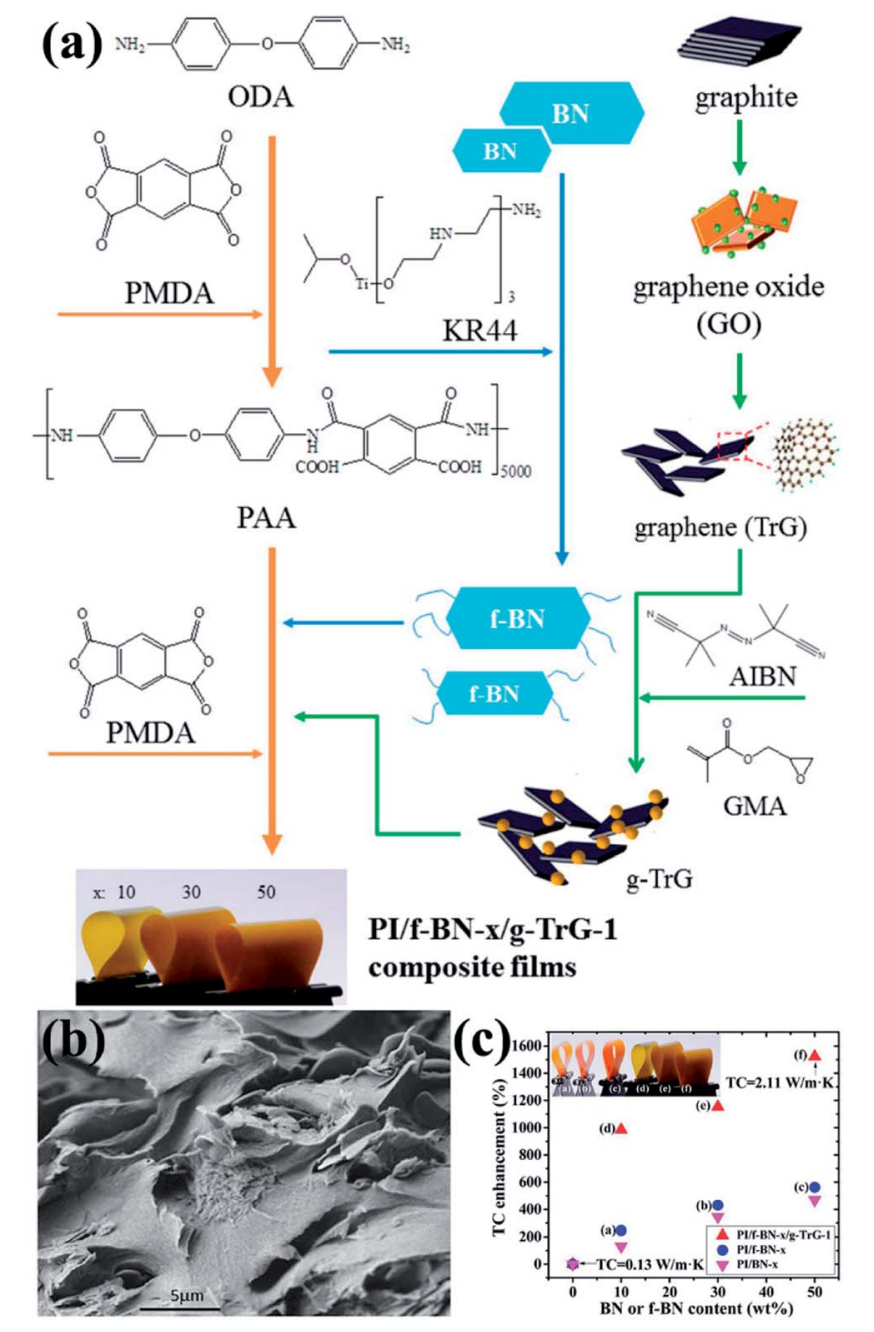

Fig. 18 (a) Preparation of fillers (f-BN and g-TrG) and composite films (PI/f-BN- $x / g-\operatorname{TrG}-1)$. (b) SEM observation of the fractured surface of $\mathrm{PI} / \mathrm{f}-\mathrm{BN}-30 / \mathrm{g}-\mathrm{TrG}-1$. (c) Variations in thermal conductivity with $\mathrm{BN}$ or f-BN contents. Reproduced with permission from ref. 123.

\section{Summary and outlook}

In the current study, the fabrication methods of BNNSs and hBN-filled composites, as well as the construction of thermally conductive networks, were summarized based on the most updated research. Studies on BNNS-filled thermally conductive polymer composites remained at their early stage for several reasons. First, the preparation of BNNSs on a large scale was difficult for a strong "lip-lip" interaction between B-N bonds on the BNNS plane that was difficult to exfoliate. Several techniques, such as mechanical and liquid exfoliation, CVD, and epitaxy, were conducted to fabricate 2D h-BN with configurations and variations in quality. Liquid exfoliation by sonicating bulk h-BN in suitable solvents would lead to a high yield. However, the lateral size of BNNS obtained by this method was usually smaller than other methods, such as CVD. Thus, it was desirable to develop effective strategies to prepare BNNS with large lateral size. The sample obtained by CVD growth could provide a high quality. However, the high temperature requirement and the transfer process, as well as the use of catalytic substrates, could be the main restrictions for the production of highly crystalline h-BN and construction of highperformance devices. Second, the properties of the interface and dispersion exerted important effects on the composite materials. The $\mathrm{BN}$ nanostructure was difficult to disperse uniformly in the polymer matrix due to its inert surface. Generally, the universal method used to improve the interface between BNNSs and the polymer matrix was surface modification. The common groups were identified as the hydroxyl group and the amino group. The hydroxyl group was connected to the $\mathrm{B}$ site, whereas the amino group was hydrogenated at the $\mathrm{N}$ site. Surface modification of h-BN was an optimal method to decrease the interface thermal resistance among the fillers and the matrix, as well as to promote good dispersion. In addition, since ball milling was based on mechanochemistry, it was found to be a good protocol to improve the interface and dispersion between fillers and matrix. However, this inevitably sacrificed the crystallinity of the fillers due to the intense shear force introduced by the ball milling process. Thus, it was desirable to develop an effective method to promote the dispersion of fillers in the matrix as well as maintain the quality of the fillers. Third, the strategies for constructing thermally conductive pathways have rarely been reported. Owing to the anisotropic thermal performance of $2 \mathrm{D}$ h-BN, the orientation preferred to prepare a composite with a high thermal conductivity in a special direction. 3D networks in perpendicular and parallel directions could lead to a high thermal conductivity. However, the strategies for constructing orientation or $3 \mathrm{D}$ networks remained limited. In addition, mixing hybrid fillers was a significant method used to form and improve heat conduction. However, the interface between nanoparticles and BNNS has great influence on the heat transfer in the hybrids. Therefore, the synergistic effect between BNNS and other functional materials, especially different polymers and various nanoparticles, remained to be exploited in the near future.

\section{Conflicts of interest}

There are no conflicts of interest to declare.

\section{Acknowledgements}

This work was supported by the National Natural Science Foundation of China (No. 51522211, 51602339 and 51703241), the Key Research Program of Frontier Science of Chinese Academy of Sciences (No. QYZDB-SSW-SLH031), the Thousand Youth Talents Plan, the Postdoctoral Foundation of China (No. 2016M601905 and 2017M621855), the Natural Science Foundation of Jiangsu Province, China (No. BK20160399), the Postdoctoral Foundation of Jiangsu Province (No. 1601065B), and the Science and Technology Project of Suzhou, China (No. SZS201508). 


\section{References}

1 D. Lu and C. P. Wong, Materials for advanced packaging, Springer, New York, 2009.

2 C. P. Wong, K. S. Moon and Y. Li, Nano-bio-electronic, photonic and MEMS packaging, Springer, New York, 2010.

3 A. L. Moore and L. Shi, Mater. Today, 2014, 17, 163-174.

4 Y. X. Wang, N. Xu, D. Y. Li and J. Zhu, Adv. Funct. Mater., 2017, 27, 1604134.

5 A. A. Balandin, S. Ghosh, W. Z. Bao, I. Calizo, D. Teweldebrhan, F. Miao and C. N. Lau, Nano Lett., 2008, 8, 902-907.

6 H. S. Kim, J. H. Kim, W. Y. Kim, H. S. Lee, S. Y. Kim and M. S. Khil, Carbon, 2017, 119, 40-46.

7 Z. Luo, J. Maassen, Y. X. Deng, Y. C. Du, R. P. Garrelts, M. S. Lundstrom, P. D. Ye and X. F. Xu, Nat. Commun., 2015, 6, 8572 .

8 C. R. Dean, A. F. Young, I. Meric, C. Lee, L. Wang, S. Sorgenfrei, K. Watanabe, T. Taniguchi, P. Kim, K. L. Shepard and J. Hone, Nat. Nanotechnol., 2010, 5, 722-726.

9 C. Zhi, Y. Bando, T. Terao, C. Tang, H. Kuwahara and D. Golberg, Adv. Funct. Mater., 2009, 19, 1857-1862.

10 K. C. Yung and H. Liem, J. Appl. Polym. Sci., 2007, 106, 35873591.

11 Y. Xu and D. D. L. Chung, Compos. Interfaces, 2000, 7, 243256.

12 Z. Lin, Y. Liu, S. Raghavan, K. S. Moon, S. K. Sitaraman and C. P. Wong, ACS Appl. Mater. Interfaces, 2013, 5, 7633-7640.

13 H. S. Lim, J. W. Oh, S. Y. Kim, M. J. Yoo, S. D. Park and W. S. Lee, Chem. Mater., 2013, 25, 3315-3319.

14 Z. Kuang, Y. Chen, Y. Lu, L. Liu, S. Hu, S. Wen, Y. Mao and L. Zhang, Small, 2015, 11, 1655-1659.

15 D. Golberg, Y. Bando, Y. Huang, T. Terao, M. Mitome, C. Tang and C. Zhi, ACS Nano, 2010, 4, 2979-2993.

16 G. R. Bhimanapati, N. R. Glavin and J. A. Robinson, Semicond. Semimetals, 2016, 95, 101-147.

17 W. L. Song, P. Wang, L. Cao, A. Anderson, M. J. Meziani, A. J. Farr and Y. P. Sun, Angew. Chem., Int. Ed., 2012, 51, 6498-6501.

18 L. Boldrin, F. Scarpa, R. Chowdhury and S. Adhikari, Nanotechnology, 2011, 22, 505702.

19 K. Rajesh, G. Rajasekaran and P. Avinash, Nanotechnology, 2016, 27, 085706.

20 J. C. Meyer, A. Chuvilin, G. Algara-Siller, J. Biskupek and U. Kaiser, Nano Lett., 2009, 9, 2683-2689.

21 R. V. Gorbachev, I. Riaz, R. R. Nair, R. Jalil, L. Britnell, B. D. Belle, E. W. Hill, K. S. Novoselov, K. Watanabe, T. Taniguchi, A. K. Geim and P. Blake, Small, 2011, 7, 465-468.

22 D. Pacilé, J. C. Meyer, Ç. Ö. Girit and A. Zettl, Appl. Phys. Lett., 2008, 92, 133107.

23 L. H. Li, Y. Chen, G. Behan, H. Zhang, M. Petravic and A. M. Glushenkov, J. Mater. Chem., 2011, 21, 11862.

24 Deepika, L. H. Li, A. M. Glushenkov, S. K. Hait, P. Hodgson and Y. Chen, Sci. Rep., 2014, 4, 7288.
25 D. Fan, J. Feng, J. Liu, T. Gao, Z. Ye, M. Chen and X. Lv, Ceram. Int., 2016, 42, 7155-7163.

26 Y. Yao, Z. Lin, Z. Li, X. Song, K. S. Moon and C. P. Wong, J. Mater. Chem., 2012, 22, 13494.

27 Z. Lin, A. McNamara, Y. Liu, K. S. Moon and C. P. Wong, Compos. Sci. Technol., 2014, 90, 123-128.

28 L. Lin, X. Zhitao, H. Daqiang, W. Guotao, L. Bin and C. Ping, Chem. Lett., 2013, 42, 1415-1416.

29 W. Q. Han, L. Wu, Y. Zhu, K. Watanabe and T. Taniguchi, Appl. Phys. Lett., 2008, 93, 223103.

30 Y. Lin, T. V. Williams, T. B. Xu, W. Cao, H. E. Elsayed-Ali and J. W. Connell, J. Phys. Chem. C, 2011, 115, 2679-2685.

31 R. J. Smith, P. J. King, M. Lotya, C. Wirtz, U. Khan, S. De, A. O'Neill, G. S. Duesberg, J. C. Grunlan, G. Moriarty, J. Chen, J. Wang, A. I. Minett, V. Nicolosi and J. N. Coleman, Adv. Mater., 2011, 23, 3944-3948.

32 C. Zhi, Y. Bando, C. Tang, H. Kuwahara and D. Golberg, Adv. Mater., 2009, 21, 2889-2893.

33 Y. Wang, Z. Shi and J. Yin, J. Mater. Chem., 2011, 21, 1137111377.

34 J. N. Coleman, M. Lotya, A. O'Neill, S. D. Bergin, P. J. King, U. Khan, K. Young, A. Gaucher, S. De, R. J. Smith, I. V. Shvets, S. K. Arora, G. Stanton, H. Y. Kim, K. Lee, G. T. Kim, G. S. Duesberg, T. Hallam, J. J. Boland, J. J. Wang, J. F. Donegan, J. C. Grunlan, G. Moriarty, A. Shmeliov, R. J. Nicholls, J. M. Perkins, E. M. Grieveson, K. Theuwissen, D. W. McComb, P. D. Nellist and V. Nicolosi, Science, 2011, 331, 568-571.

35 K. G. Zhou, N. N. Mao, H. X. Wang, Y. Peng and H. L. Zhang, Angew. Chem., Int. Ed., 2011, 50, 10839-10842.

36 L. Cao, S. Emami and K. Lafdi, Mater. Express, 2014, 4, 165171.

37 H. B. Cho, T. Nakayama, H. Suematsu, T. Suzuki, W. Jiang, K. Niihara, E. Song, N. S. A. Eom, S. Kim and Y. H. Choa, Compos. Sci. Technol., 2016, 129, 205-213.

38 M. T. Paffett, R. J. Simonson, P. Papin and R. T. Paine, Surf. Sci., 1990, 232, 286-296.

39 A. Nagashima, N. Tejima, Y. Gamou, T. Kawai and C. Oshima, Phys. Rev. B, 1995, 51, 4606-4613.

40 F. Müller, K. Stöwe and H. Sachdev, Chem. Mater., 2005, 17, 3464-3467.

41 W. Auwärter, H. U. Suter, H. Sachdev and T. Greber, Chem. Mater., 2004, 16, 343-345.

42 M. Corso, W. Auwärter, M. Muntwiler, A. Tamai, T. Greber and J. Osterwalder, Science, 2004, 303, 217-220.

43 N. A. Vinogradov, A. A. Zakharov, M. L. Ng, A. Mikkelsen, E. Lundgren, N. Mårtensson and A. B. Preobrajenski, Langmuir, 2012, 28, 1775-1781.

44 F. Müller, S. Hüfner and H. Sachdev, Surf. Sci., 2008, 602, 3467-3476.

45 M. P. Allan, S. Berner, M. Corso, T. Greber and J. Osterwalder, Nanoscale Res. Lett., 2007, 2, 94.

46 A. B. Preobrajenski, M. A. Nesterov, M. L. Ng, A. S. Vinogradov and N. Mårtensson, Chem. Phys. Lett., 2007, 446, 119-123.

47 A. B. Preobrajenski, A. S. Vinogradov and N. Mårtensson, Surf. Sci., 2005, 582, 21-30. 
48 M. Morscher, M. Corso, T. Greber and J. Osterwalder, Surf. Sci., 2006, 600, 3280-3284.

49 A. Hemmi, C. Bernard, H. Cun, S. Roth, M. Klöckner, T. Kälin, M. Weinl, S. Gsell, M. Schreck, J. Osterwalder and T. Greber, Rev. Sci. Instrum., 2014, 85, 035101.

50 A. R. Jang, S. Hong, C. Hyun, S. I. Yoon, G. Kim, H. Y. Jeong, T. J. Shin, S. O. Park, K. Wong, S. K. Kwak, N. Park, K. Yu, E. Choi, A. Mishchenko, F. Withers, K. S. Novoselov, H. Lim and H. S. Shin, Nano Lett., 2016, 16, 3360-3366.

51 A. Ismach, H. Chou, D. A. Ferrer, Y. Wu, S. McDonnell, H. C. Floresca, A. Covacevich, C. Pope, R. Piner, M. J. Kim, R. M. Wallace, L. Colombo and R. S. Ruoff, ACS Nano, 2012, 6, 6378-6385.

52 R. Y. Tay, H. Li, S. H. Tsang, M. Zhu, M. Loeblein, L. Jing, F. N. Leong and E. H. T. Teo, Chem. Mater., 2016, 28, 2180-2190.

53 J. H. Park, S. H. Choi, J. Zhao, S. Song, W. Yang, S. M. Kim, K. K. Kim and Y. H. Lee, Curr. Appl. Phys., 2016, 16, 12291235.

54 G. Kim, A. R. Jang, H. Y. Jeong, Z. Lee, D. J. Kang and H. S. Shin, Nano Lett., 2013, 13, 1834-1839.

55 J. H. Park, J. C. Park, S. J. Yun, H. Kim, D. H. Luong, S. M. Kim, S. H. Choi, W. Yang, J. Kong, K. K. Kim and Y. H. Lee, ACS Nano, 2014, 8, 8520-8528.

56 Y. H. Lee, K. K. Liu, A. Y. Lu, C. Y. Wu, C. T. Lin, W. Zhang, C. Y. Su, C. L. Hsu, T. W. Lin, K. H. Wei, Y. Shi and L. J. Li, RSC Adv., 2012, 2, 111-115.

57 Y. Shi, C. Hamsen, X. Jia, K. K. Kim, A. Reina, M. Hofmann, A. L. Hsu, K. Zhang, H. Li, Z. Y. Juang, M. S. Dresselhaus, L. J. Li and J. Kong, Nano Lett., 2010, 10, 4134-4139.

58 K. H. Lee, H. J. Shin, J. Lee, I. Y. Lee, G. H. Kim, J. Y. Choi and S. W. Kim, Nano Lett., 2012, 12, 714-718.

59 G. Ning, W. Jinquan, F. Lili, J. Yi, L. Dayao, Z. Hongwei, W. Kunlin and W. Dehai, Nanotechnology, 2012, 23, 415605.

60 R. Y. Tay, M. H. Griep, G. Mallick, S. H. Tsang, R. S. Singh, T. Tumlin, E. H. T. Teo and S. P. Karna, Nano Lett., 2014, 14, 839-846.

61 L. Wang, B. Wu, J. Chen, H. Liu, P. Hu and Y. Liu, Adv. Mater., 2014, 26, 1559-1564.

62 H. Jaehyun, L. Jun-Young, K. Heemin and Y. Jong-Souk, Nanotechnology, 2014, 25, 145604.

63 R. Y. Tay, H. J. Park, G. H. Ryu, D. Tan, S. H. Tsang, H. Li, W. Liu, E. H. T. Teo, Z. Lee, Y. Lifshitz and R. S. Ruoff, Nanoscale, 2016, 8, 2434-2444.

64 G. Lu, T. Wu, Q. Yuan, H. Wang, H. Wang, F. Ding, X. Xie and M. Jiang, Nat. Commun., 2015, 6, 6160.

65 C. M. Orofeo, S. Suzuki, H. Kageshima and H. Hibino, Nano Res., 2013, 6, 335-347.

66 S. Caneva, R. S. Weatherup, B. C. Bayer, B. Brennan, S. J. Spencer, K. Mingard, A. Cabrero-Vilatela, C. Baehtz, A. J. Pollard and S. Hofmann, Nano Lett., 2015, 15, 18671875.

67 K. H. Lee, H. J. Shin, B. Kumar, H. S. Kim, J. Lee, R. Bhatia, S. H. Kim, I. Y. Lee, H. S. Lee, G. H. Kim, J. B. Yoo, J. Y. Choi and S. W. Kim, Angew. Chem., Int. Ed., 2014, 53, 1149311497.
68 Q. Li, Y. Jie, L. Mingyu, L. Fei and B. Xuedong, Nanotechnology, 2011, 22, 215602.

69 A. Pakdel, C. Zhi, Y. Bando, T. Nakayama and D. Golberg, ACS Nano, 2011, 5, 6507-6515.

70 R. Y. Tay, S. H. Tsang, M. Loeblein, W. L. Chow, G. C. Loh, J. W. Toh, S. L. Ang and E. H. T. Teo, Appl. Phys. Lett., 2015, 106, 101901.

71 F. Xiao, S. Naficy, G. Casillas, M. H. Khan, T. Katkus, L. Jiang, H. Liu, H. Li and Z. Huang, Adv. Mater., 2015, 27, 7196-7203.

72 Y. Xu and D. D. L. Chung, Compos. Interfaces, 2012, 7, 243256.

$73 \mathrm{H} . \mathrm{Wu}$ and M. R. Kessler, ACS Appl. Mater. Interfaces, 2015, 7, 5915-5926.

74 H. Shen, J. Guo, H. Wang, N. Zhao and J. Xu, ACS Appl. Mater. Interfaces, 2015, 7, 5701-5708.

75 J. Yu, X. Huang, C. Wu, X. Wu, G. Wang and P. Jiang, Polymer, 2012, 53, 471-480.

76 X. Wang, A. Pakdel, J. Zhang, Q. Weng, T. Zhai, C. Zhi, D. Golberg and Y. Bando, Nanoscale Res. Lett., 2012, 7, 662.

77 W. L. Song, P. Wang, L. Cao, A. Anderson, M. J. Meziani, A. J. Farr and Y. P. Sun, Angew. Chem., Int. Ed., 2012, 51, 6498-6501.

78 X. Zeng, L. Ye, S. Yu, H. Li, R. Sun, J. Xu and C. P. Wong, Nanoscale, 2015, 7, 6774-6781.

79 R. C. Zhang, D. Sun, A. Lu, S. Askari, M. Macias-Montero, P. Joseph, D. Dixon, K. Ostrikov, P. Maguire and D. Mariotti, ACS Appl. Mater. Interfaces, 2016, 8, 1356713572.

80 T. Morishita and H. Okamoto, ACS Appl. Mater. Interfaces, 2016, 8, 27064-27073.

81 K. Kim, M. Kim, Y. Hwang and J. Kim, Ceram. Int., 2014, 40, 2047-2056.

82 J. Yu, H. Mo and P. Jiang, Polym. Adv. Technol., 2015, 26, 514-520.

83 X. B. Wang, Q. Weng, X. Wang, X. Li, J. Zhang, F. Liu, X. F. Jiang, H. Guo, N. Xu, D. Golberg and Y. Bando, ACS Nano, 2014, 8, 9081-9088.

84 K. Kim, M. Kim and J. Kim, Ceram. Int., 2014, 40, 1093310943.

85 S. Xie, O. M. Istrate, P. May, S. Barwich, A. P. Bell, U. Khan and J. N. Coleman, Nanoscale, 2015, 7, 4443-4450.

86 X. Wu, H. Liu, Z. Tang and B. Guo, Compos. Sci. Technol., 2016, 123, 179-186.

87 X. Huang, S. Wang, M. Zhu, K. Yang, P. Jiang, Y. Bando, D. Golberg and C. Zhi, Nanotechnology, 2015, 26, 015705.

88 L. Qin, G. Li, J. Hou, X. Yu, H. Ding, Q. Zhang, N. Wang and X. Qu, Polym. Compos., 2015, 36, 1675-1684.

89 Z. Cui, A. P. Martinez and D. H. Adamson, Nanoscale, 2015, 7, 10193-10197.

90 J. Lee, H. Jung, S. Yu, S. Man Cho, V. K. Tiwari, D. Babu Velusamy and C. Park, Chem.-Asian J., 2016, 11, 1921-1928.

91 D. Lee, B. Lee, K. H. Park, H. J. Ryu, S. Jeon and S. H. Hong, Nano Lett., 2015, 15, 1238-1244.

92 H. J. Ahn, S. H. Cha, W. S. Lee and E. S. Kim, Thermochim. Acta, 2014, 591, 96-100. 
93 H. J. Ahn, Y. J. Eoh, S. D. Park and E. S. Kim, Thermochim. Acta, 2014, 590, 138-144.

94 S. Takahashi, Y. Imai, A. Kan, Y. Hotta and H. Ogawa, J. Alloys Compd., 2014, 615, 141-145.

95 R. M. Erb, R. Libanori, N. Rothfuchs and A. R. Studart, Science, 2012, 335, 199-204.

96 H. B. Cho, Y. Tokoi, S. Tanaka, H. Suematsu, T. Suzuki, W. Jiang, K. Niihara and T. Nakayama, Compos. Sci. Technol., 2011, 71, 1046-1052.

97 K. Kim and J. Kim, Int. J. Therm. Sci., 2016, 100, 29-36.

98 C. Yuan, B. Duan, L. Li, B. Xie, M. Huang and X. Luo, ACS Appl. Mater. Interfaces, 2015, 7, 13000-13006.

99 H. B. Cho, T. Nakayama, Y. Tokoi, S. Endo, S. Tanaka, T. Suzuki, W. Jiang, H. Suematsu and K. Niihara, Compos. Sci. Technol., 2010, 70, 1681-1686.

100 T. Fujihara, H. B. Cho, T. Nakayama, T. Suzuki, W. Jiang, H. Suematsu, H. D. Kim, K. Niihara and J. Blendell, J. Am. Ceram. Soc., 2012, 95, 369-373.

101 H. Zhu, Y. Li, Z. Fang, J. Xu, F. Cao, J. Wan, C. Preston, B. Yang and L. Hu, ACS Nano, 2014, 8, 3606-3613.

102 K. Wu, J. C. Fang, J. R. Ma, R. Huang, S. G. Chai, F. Chen and Q. Fu, ACS Appl. Mater. Interfaces, 2017, 9, 3003530045.

103 J. C. Zheng, L. Zhang, A. V. Kretinin, S. V. Morozov, Y. B. Wang, T. Wang, X. Li, F. Ren, J. Zhang and C. Y. Lu, 2D Mater., 2016, 3, 011004.

104 L. Fu, T. Wang, J. Yu, W. Dai, H. Sun, Z. Liu, R. Sun, N. Jiang, A. Yu and C. T. Lin, 2D Mater., 2017, 4, 025047.

105 X. Zeng, Y. Yao, Z. Gong, F. Wang, R. Sun, J. Xu and C. P. Wong, Small, 2015, 11, 6205-6213.

106 J. Chen, X. Huang, Y. Zhu and P. Jiang, Adv. Funct. Mater., 2017, 27, 1604754.

107 J. Yang, L. S. Tang, R. Y. Bao, L. Bai, Z. Y. Liu, W. Yang, B. H. Xie and M. B. Yang, J. Mater. Chem. A, 2016, 4, 18841-18851.
108 B. H. Xie, X. Huang and G. J. Zhang, Compos. Sci. Technol., 2013, 85, 98-103.

109 Y. Xue, X. Jin, Y. Fan, R. Tian, X. Xu, J. Li, J. Lin, J. Zhang, L. Hu and C. Tang, Polym. Compos., 2014, 35, 1707-1715.

110 K. Kim and J. Kim, Ceram. Int., 2014, 40, 5181-5189.

111 Z. Wang, Y. Fu, W. Meng and C. Zhi, Nanoscale Res. Lett., 2014, 9, 643.

112 X. J. Wang, L. Z. Zhang and L. X. Pei, J. Appl. Polym. Sci., 2014, 131, 39550.

113 T. L. Li and S. L. Hsu, J. Phys. Chem. B, 2010, 114, 68256829.

114 K. C. Yung and H. Liem, J. Appl. Polym. Sci., 2007, 106, 3587-3591.

115 W. Y. Zhou, S. H. Qi, H. Z. Zhao and N. L. Liu, Polym. Compos., 2007, 28, 23-28.

116 T. L. Li and S. L. C. Hsu, J. Phys. Chem. B, 2010, 114, 68256829.

117 S. Kemaloglu, G. Ozkoc and A. Aytac, Thermochim. Acta, 2010, 499, 40-47.

118 L. Fang, C. Wu, R. Qian, L. Xie, K. Yang and P. Jiang, $R S C$ $A d v .$, 2014, 4, 21010-21017.

119 A. Permal, M. Devarajan, H. L. Hung, T. Zahner, D. Lacey and K. Ibrahim, J. Mater. Sci., 2016, 51, 7415-7426.

120 Y. X. Fu, Z. X. He, D. C. Mo and S. S. Lu, Appl. Therm. Eng., 2014, 66, 493-498.

121 F. Wang, X. Zeng, Y. Yao, R. Sun, J. Xu and C. P. Wong, Sci. Rep., 2016, 6, 19394.

122 Y. Yao, X. Zeng, R. Sun, J. B. Xu and C. P. Wong, ACS Appl. Mater. Interfaces, 2016, 8, 15645-15653.

123 M. H. Tsai, I. H. Tseng, J. C. Chiang and J. J. Li, ACS Appl. Mater. Interfaces, 2014, 6, 8639-8645.

124 X. Cui, P. Ding, N. Zhuang, L. Shi, N. Song and S. Tang, ACS Appl. Mater. Interfaces, 2015, 7, 19068-19075.

125 Y. Xiao, W. Wang, T. Lin, X. Chen, Y. Zhang, J. Yang, Y. Wang and Z. Zhou, J. Phys. Chem. C, 2016, 120, 63446355. 